\title{
Oxide material synthesis by combustion of organic-inorganic compositions
}

\author{
A. A. Ostroushko, O. V. Russkikh \\ Ural Federal University named after the first President of Russia B. N. Yeltsin, Ekaterinburg, Russia \\ alexander.ostroushko@urfu.ru
}

DOI 10.17586/2220-8054-2017-8-4-476-502

\begin{abstract}
This review analyzes and summarizes the research results for oxide material synthesis by combustion of organic-inorganic mixtures. We have outlined the range of physical and chemical factors influencing the precursor processes and the oxide material synthesis itself, as well as have shown the ways and options to control these processes and nanoscale materials' properties. We have highlighted several issues concerning the analysis methods for the resulting materials and processes. We have exemplified the practical implementation of the methods under discussion.
\end{abstract}

Keywords: synthesis, oxides, combustion method, organic-inorganic compositions.

Received: 15 March 2017

Revised: 4 August 2017

\section{Introduction}

Among the methods for oxide compounds and oxide-based materials, those using salts of different composition as starting materials and the reaction environments occupy an important place both in terms of scientific research [1-13] and for practical purposes [14-18]. These methods for oxide material synthesis have been proposed as alternative for solid-phase synthesis of oxide reagents, the implementation of which requires, as a rule, hightemperature and long-term cyclic thermal powder treatment [19-25]. It should be noted that there are methods for solid-phase synthesis with high-rate solid-phase chemical oxide interaction, however, the number of such methods is limited [26-33].

Solid-phase oxide reagent synthesis does not often make it possible to produce single-phase products if their thermal stability is limited. Such instances may be the synthesis of $\mathrm{LaNiO}_{3}$ [34-36], $\mathrm{BiFeO}_{3}$ [20,37-39]. In the source-oxide synthesis of $\mathrm{LaNiO}_{3}$ and $\mathrm{BiFeO}_{3}$, as noted in [20,34], the acceptable process rate is achieved at temperatures exceeding the thermal stability interval of these compounds. The application of such techniques as solid-phase nanoscale oxide powder synthesis does not always yield positive results. Such cases are addressed, e.g. in [40-42]. The method utilizing thin-film layered complex composition oxides for synthesis, sometimes permits high-rate solid-phase interaction of components at relatively low temperatures [29,32], although this method is not always feasible since it is technologically complex to produce such compositions. It is not always possible to sufficiently increase the solid-phase interaction of oxide powders by using mechanochemical synthesis [43-50]. The scope of high-rate chemical solid-phase reactions at relatively mild temperature conditions, as mentioned in [28], is somewhat limited.

In this regard, various alternatives of the "soft chemistry" methods [14,51-85] have been rapidly developed recently. Various "soft chemistry" methods have helped produce a large number of oxide compounds of varying compositions, structure, dispersity, including as nano-powders. In a great number of "soft chemistry" methods, the disadvantages are, as a rule, complex preparation of precursors and the source reaction compositions, complex instrumentation for the synthetic process, low reaction yields. In some cases, it makes it impractical to use such methods. Thus, despite the prospects of developing "soft chemistry" methods to produce oxide materials, especially nanomaterials, in many cases, these methods cannot, for the above reason, satisfy the demands in the synthesis of oxide materials, including nanostructured materials.

The methods that will be discussed below are based on the pyrolysis of mixtures consisting of salts or related forms of the source reagents and the organic part. Unlike the Pechini method [14], this review will consider the oxide synthesis processes as occurring in terms of redox reactions that are considerably exothermic. The initial state of the precursors used is, as a rule, a solution. Therefore, these methods are termed Solution Combustion Synthesis (SCS) [86,87]. If nitrates or other oxidizing agents are used as salt forms, the pyrolysis processes can occur after their initiation, in particular the thermal one, in modes similar to that of self-propagating high-temperature synthesis (SHS) [88-91].

Pyrolytic synthesis may be related to the group of methods in which the phase formation processes take place in conditions far removed from equilibrium [92]. Such methods include co-sedimentation, solvent replacement, 
thermal salt decomposition, spray pyrolysis, Sol-gel methods, cryochemical synthesis, mechanochemical synthesis, etc.

In general, methods that use salts as reagents allow reduction of the synthetic temperature and duration, producing oxide compounds in the form of fine powders, including nano-powders. Herewith, some of these methods have inherent disadvantages such as possible lack of the resulting product homogeneity due to spatial separation of reagents during the synthetic process [29]. The implementation of some of these methods may lead to waste products, requiring disposal or recycling, for example, hazardous wastewater, toxic gases. The methods related to SCS are relatively simple, allowing mitigation of the negative aspects inherent in many methods where salts are applied as reagents. Different variants of SCS methods have enabled synthesis of a large number of oxide compounds in the form of nano-powders which are promising for functional and structural material manufacture [93-136]. For this reason, the SCS methods have recently attracted considerable attention.

For this review, one of the objectives is to address the specificities of SCS methods and those physicochemical aspects that are important for the most effective SCS implementation. The review is based on the results obtained by the authors, which have not been hitherto analyzed and summarized in a review on the oxide synthesis of by SCS method. In this respect, this review can be considered as complementary to the currently available reviews on material production by SCS methodology [137-148].

Different materials have been produced using compositions containing water-soluble nonionic surface-active polymers, mainly Polyvinyl alcohol (PVA), Polyvinylpyrrolidone (PVP) and metal nitrates as the salt components. For example, high-temperature superconductors [149-154], oxide magnetic materials with magnetoplumbite structure [155], perovskite-structured compounds [156-161] with catalytic and other properties allowing their application as catalysts for atmospheric protection from toxic emissions, as components of solid oxide fuel cells, electrochemical oxygen source and in other fields, solid solutions based on fluorite-type cerium dioxide [162] which also has a variety of applications, monazite-type alkali metal doped lanthanum vanadate [127] which was used as a catalyst for soot oxidation by nitrogen oxides and atmosheric oxygen, and other materials. The oxides, as previously mentioned, can be obtained not only as powders, but as deposited coatings [151-154,156,157,160,163]. In particular, nanostructured catalysts for atmosphere protection from toxic emissions have been obtained by the SCS method [126, 127, 130,156-158,160,164].

In addition to the above-mentioned water-soluble polymers, in some cases, other compounds may be used as the organic component as well: polymethyl methacrylate, polyacrylamide, polyethylene glycol (PEG), methylcellulose (MC). The application of such polymers arises from their specific properties, in particular, melts flowing into cavities may be produced when heating PEG-based systems. MC is able to form gels at relatively low concentrations. One SCS method utilizes a process whereby initial solutions are evaporated until reaching the initial temperature of spontaneous pyrolysis. The other is performed by drying the composition at a relatively low temperature, ambient evaporation, vacuum, low infrared heating drying, etc. The second variant of the SCS methodology is more frequently used for the production of functional coatings.

In materials technology, the potential to produce oxide materials by pyrolytic methods not only as powders but as coatings on various carriers is important. Given this fact, a special SCS variant was suggested [165], in which the nonionic surfactant water-soluble polymers having, inter alia, a good film-forming ability were used as the organic precursor. SCS coating production will also be discussed in this review.

The results of oxide material synthesis by SCS method are influenced by a range of physical and chemical factors which should be logically considered in the same sequence of basic procedures of final production. The most important material features ensuring their functional properties include phase composition, homogeneous chemical composition of phases or the specified ratio of components within them, dimensions and morphology of particles, their boundary or surface state, including the mobility of components which is manifested, in particular, in sintering processes $[166,167]$, etc.. At the first stage of precursor production, one of the main tasks is to ensure homogeneity. Herewith, this requirement remains relevant for removal of the solvent during its evaporation and precursor drying. The second of the most important aspects is the actual pyrolysis (combustion) of the mixtures. The choice of systems containing inorganic and organic components has a significant effect on the combustion characteristics and the products' properties. Let us add that the target additives such as low-ash content surfactants improve the source composition spreading on the carrier surface etc., may sometimes be introduced into the polymer-salt compositions (PSC). Water is a universal solvent for precursors, although non-aqueous solutions can be also used to produce oxides.

\section{Organic-inorganic precursors}

The existence of homogeneous precursors is determined by both thermodynamic and kinetic factors. In order to thermodynamically analyze the possible of existence of homogeneously consistent systems, it is customary to use 
phase state diagrams which are the physicochemical basis for developing new materials and technologies [168]. In cases of precursors being produced at atmospheric pressure and room temperature, one can use isobaric-isothermal sections of state diagrams. It should be noted that the presence of nitrate salts in the precursors is in no way a strict requirement. For instance, formates [151], acetates [169], and other thermally degradable forms of the respective metals may be used. This choice affects the specificities of both the precursor production and the combustion process. A number of metals such as vanadium, molybdenum, tungsten may be included in source compositions as part of oxygen-containing anions (in particular, polyoxometallates): $\mathrm{VO}_{4}^{-} \mathrm{Mo}_{7} \mathrm{O}_{24}^{6-}, \mathrm{W}_{12} \mathrm{O}_{41}^{10-}$. However, in case of cationic metal forms, the nitrate systems which ensure active exothermic reactions during pyrolysis are used most frequently. In fact, metals can also constitute part of the precursor compositions as oxygen-containing cations, such as zirconyl $\mathrm{ZrO}^{2+}$. In [170-177], the corresponding phase diagrams were made for some rather typical representatives of polymer-salt-water systems used as precursors. Similar diagrams can also be made for systems containing low-molecular organic components. The common system type is one in which diagrams have areas of homogeneity separated by areas where two or three phases coexist (Fig. 1-4). Limited homogenous areas are adjacent to each of the triangle vertices where the system is enriched with one of components: aqueous solutions of the corresponding salt and polymer, the polymer matrix comprising water and a salt component, and a salt phase which may include both water and a polymer component. The two-phase areas include, for example, aqueous saline solution containing a polymer gel, drip formation of an aqueous saline solution in the polymer film (Fig. 5), the salt crystals in the polymer matrix or in an aqueous solution, etc. Upon removal of solvent (water), the system composition passes through a line (Fig. 1, the dotted line with long dashes) which corresponds to the constant ratio between the salt and polymer weight, transitioning to heterogeneous areas, including the three-phase diagram segment. This type of diagram is typical for polymers which partially mix with water, such as PVA, as well as for organic components (e.g., glycine) which are sparingly water-soluble.

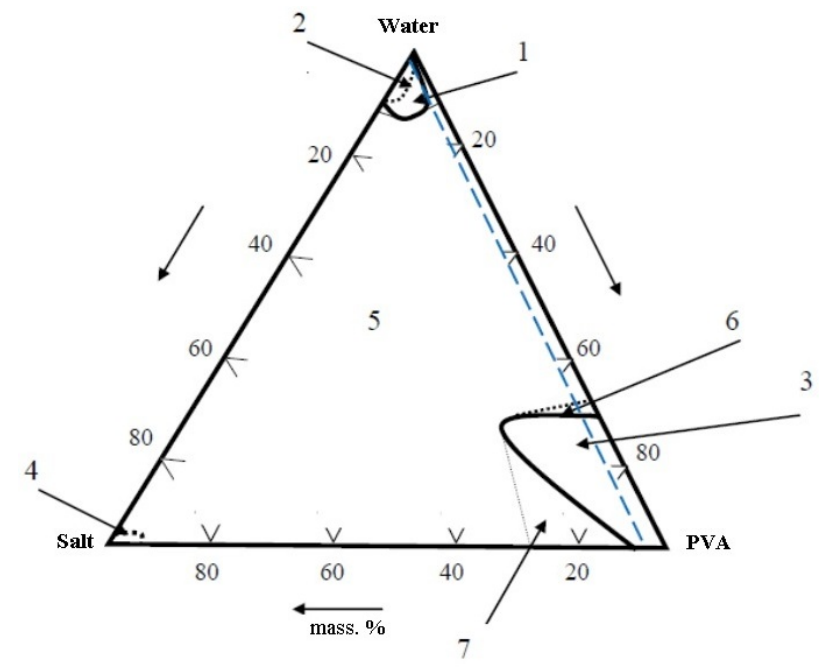

FIG. 1. Isothermal phase diagram section, tetrahydrate heptamolybdate ammonium - water polyvinyl alcohol (PVA) system. 1 - area of existence of homogeneous polymer-saline solutions in water in the light; 2 - the same in the dark; 3 - homogeneous area of solid-phase samples; 4 hypothetical solid, polymer-containing, salt component-based solutions; 5 - area of three-phase coexistence: liquid polymer-saline solutions, solid polymer-saline solutions, and saline phase; 6 - biphasic area with a solid matrix, comprising solid and liquid polymer-saline solutions; 7 biphasic area corresponding to the equilibrium between the solid polymer-saline solutions and the salt phase.

Despite the fact that the precursor homogeneity should, as a rule, be broken when removing the solvent in the above system, there are a number of factors, due to which the occurrence of multiphase systems can be substantially inhibited. Thus, the possibility to adsorb the organic components on the surface of the emerging salt microcrystals has a positive effect on the decreasing trend in system phase separation. In particular, the polymeric shell prevents their growth by blocking, at least partially, the ion supply from the solution $[178,179]$. The increase in the rate of solvent removal, e.g. in precursor vacuuming, allows quicker passage through heterogeneous areas of the phase diagram, and in some cases, phases which were supposed to have formed do not have time to take shape spatially. This leads, for example, to the formation of metastable glassy films. Under similar conditions, the polymers of 


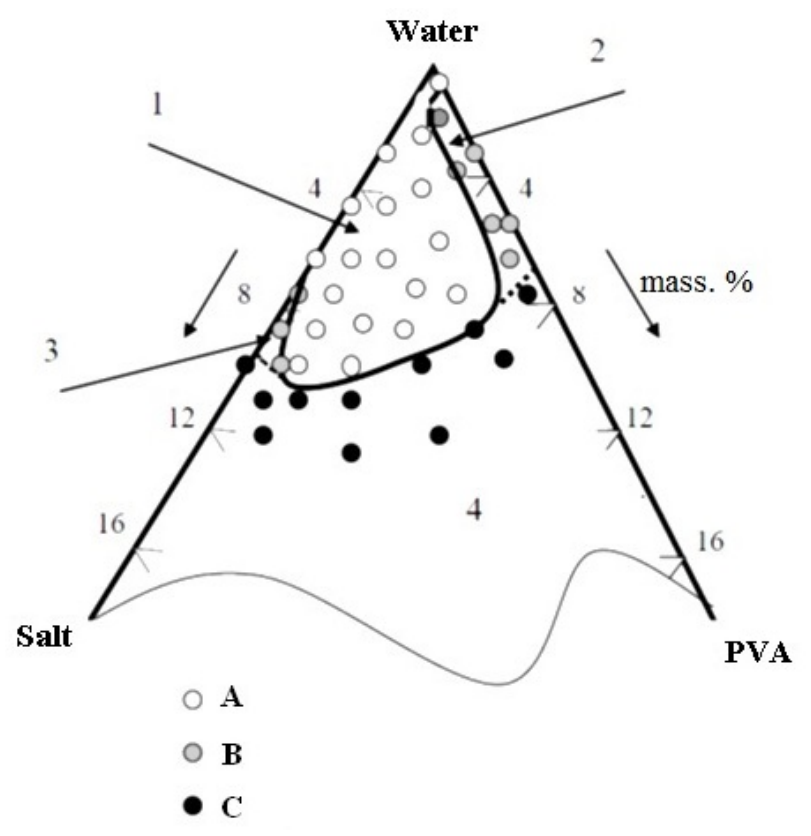

FIG. 2. A fragment of the phase salt - water - polymer diagram in the light. A - single-phase area of aqueous polymer-saline solutions (1); B - biphasic areas of existence of liquid and solid solutions with liquid disperse medium (2) and of the liquid solution and the salt phase (3); C triphasic area of coexistence of liquid and solid solutions with the salt phase (4)

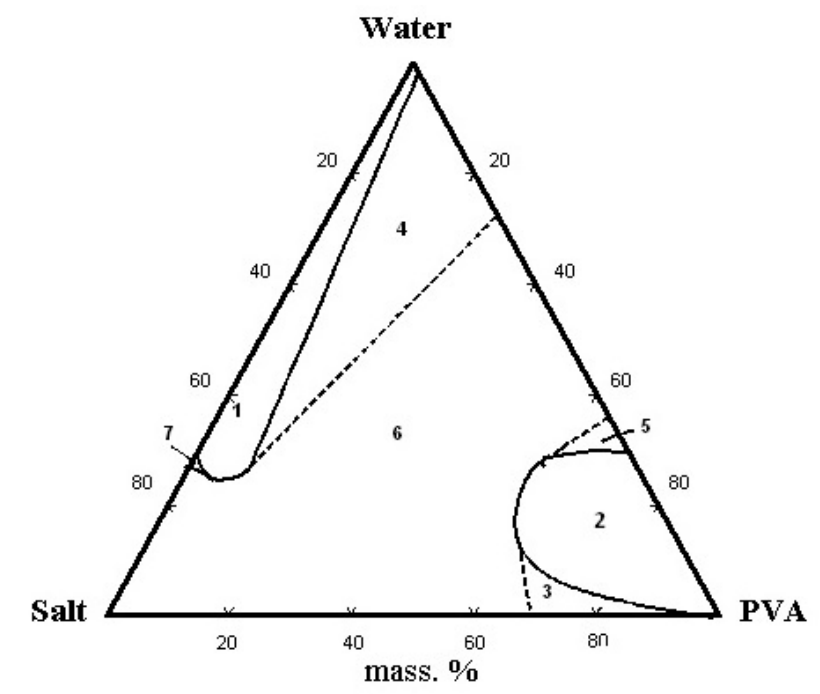

FIG. 3. Isothermal section of the phase diagram of the $\mathrm{La}\left(\mathrm{NO}_{3}\right)_{3} \cdot 6 \mathrm{H}_{2} \mathrm{O}$ system - polyvinyl alcohol - water at room temperature. 1,2 - areas of homogeneous solutions (aqueous and polymer-based), 3, 4, 5, 7 - biphasic areas (with salt crystallization - 5, 7, gelation - 4, drip inclusions in the polymer matrix), 6 - triphasic area with gelation and crystalline salt precipitation occurred simultaneously 


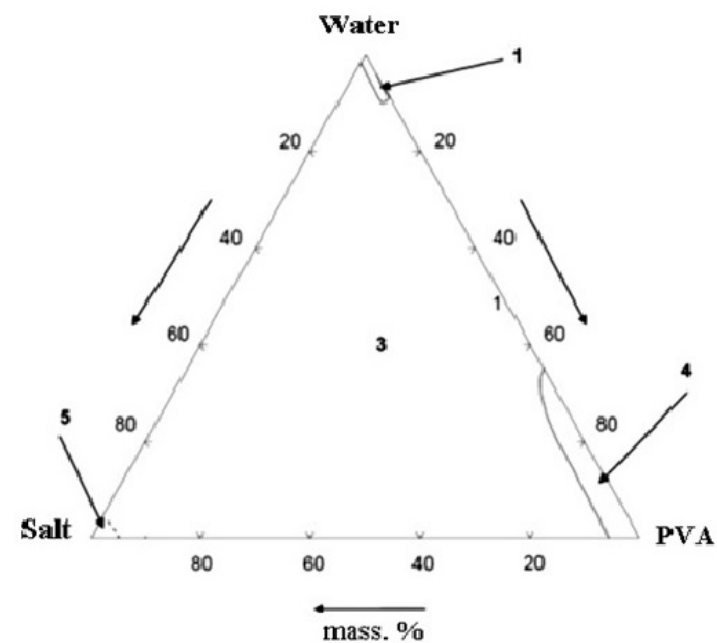

(a)

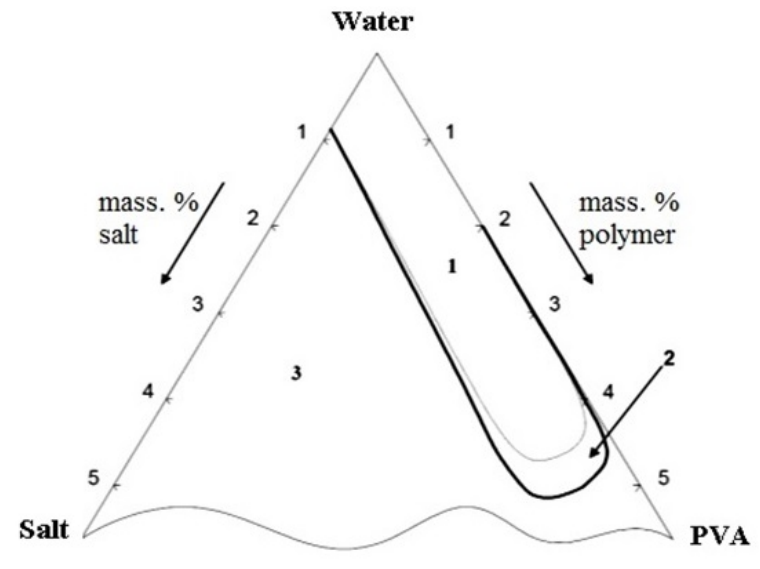

(b)

FIG. 4. Isothermal section of phase diagram of the ammonium vanadate system - polyvinyl alcohol - water at room temperature: 1 - area of homogeneous aqueous solutions under natural light; 2 - the same after exposure to UV radiation; 3 - heterogeneous area; 4 - area of homogeneous polyvinyl alcohol-based solutions; 5 - polymer-saline, ammonium vanadate based complexes

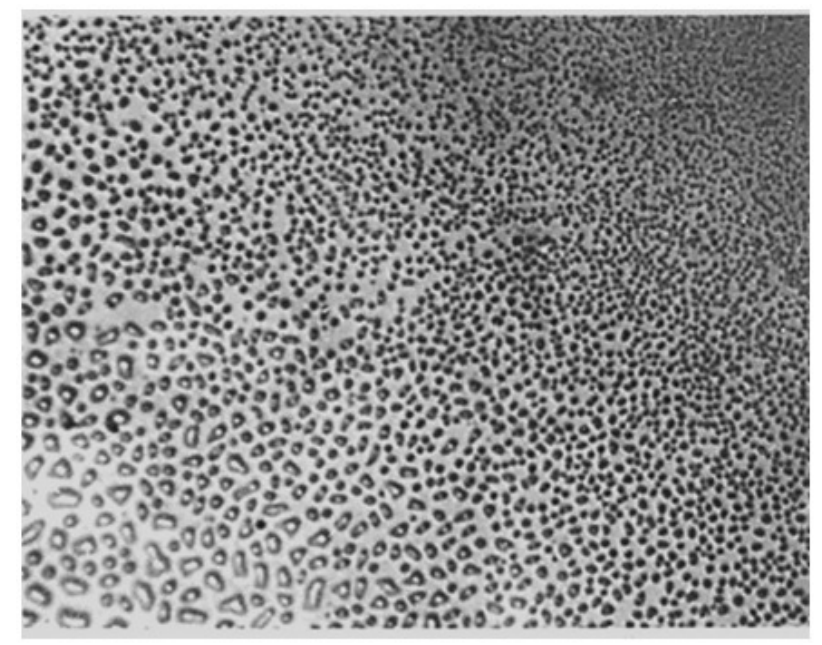

FIG. 5. Micrograph of drip formations in the PVA film containing copper nitrate $(200 \mathrm{x})$

lower molecular weight are better able to suppress the growth of crystallites [153], which is a result of fewer steric difficulties in their adsorption on the solid-phase nuclei.

The polymers and organic compounds which are absolutely water-miscible are characterized by another type of phase diagram (Figs. 6-8). This type allows solvent removal while remaining within the homogeneous region. If the salt component dissolves rather poorly in water, the homogeneity range is narrow and is difficult to be practically employed (Fig. 6). The most advantageous type to preserve the precursor homogeneity is a diagram with good salt solubility (Figs. 7,8). It involves, in particular, those practically important systems which include PVP and soluble metal nitrates such as lanthanum and its analogs, as well as of transition metals, e.g. copper, nickel, cobalt, manganese, etc. Glycerin-inclusive systems are also practically relevant. We should note that such systems are characterized by the existence of a liquid-phase immiscibility area, i.e. the existence of the area in which two liquid phases coexist. The availability of liquid-phase immiscibility (Figs. 9,10) can be observed depending on existence of a lower or upper critical point in the phase diagram when the liquid precursor temperature is changed, for example, when it is heated for water evaporation, which must also be considered in practical terms.

In the ammonium heptamolybdate - polyvinylpyrrolidone - water system, in particular, at room temperature (Fig. 9), there is a field of homogeneous solutions (1), the areas of the salt component crystallization (2) and (3), 


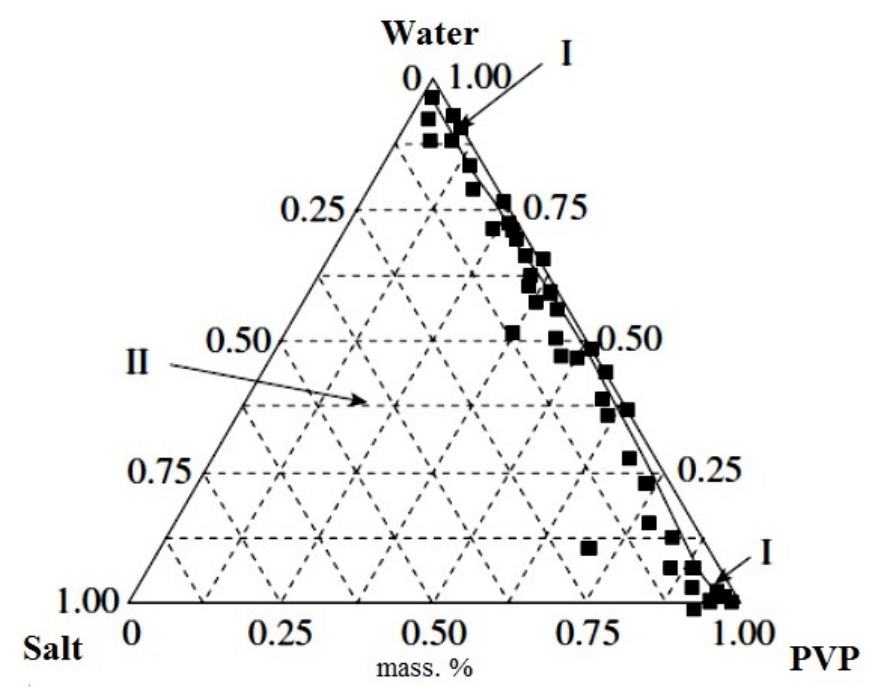

FIG. 6. Phase state diagram for the ammonium tungstate - polyvinylpyrrolidone - water system. The content of components in mass proportions. I - the area of homogeneous solutions; II heterogeneous area of coexistence of the salt phase and the solution

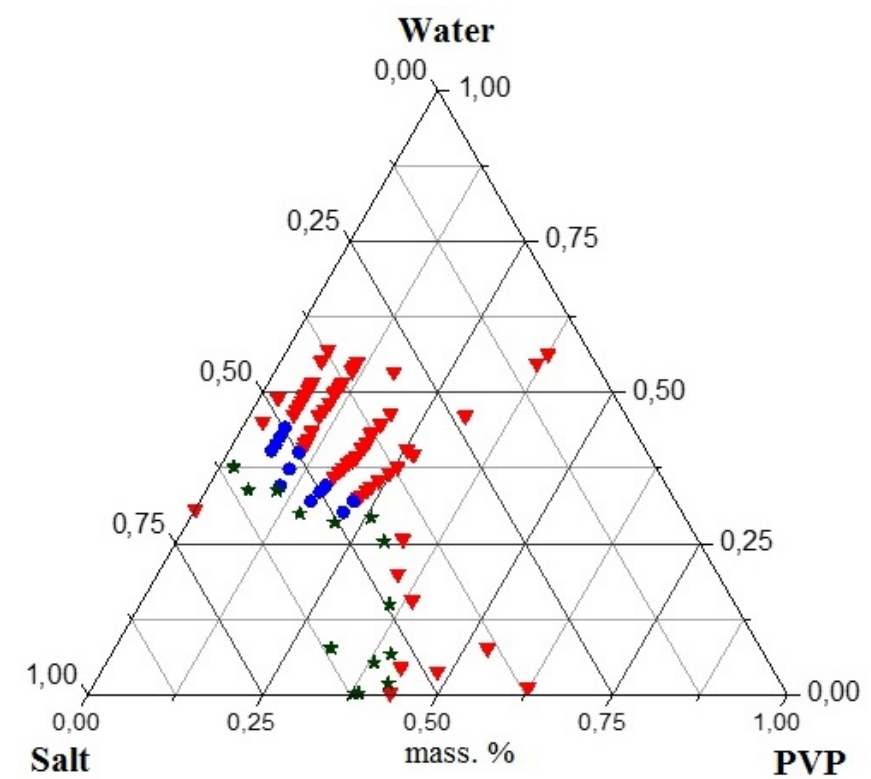

FIG. 7. Isothermal section of the phase state diagram for the lanthanum nitrate - polyvinylpyrrolidone - water system. 1 - the area of existence of homogeneous aqueous polymer-saline solutions (the respective compositions of experimental samples are marked with triangles); 2 - the area of liquid immiscibility (circles); 3 - the triphasic area of coexistence of two liquid phases and salt crystals (asterisks) 


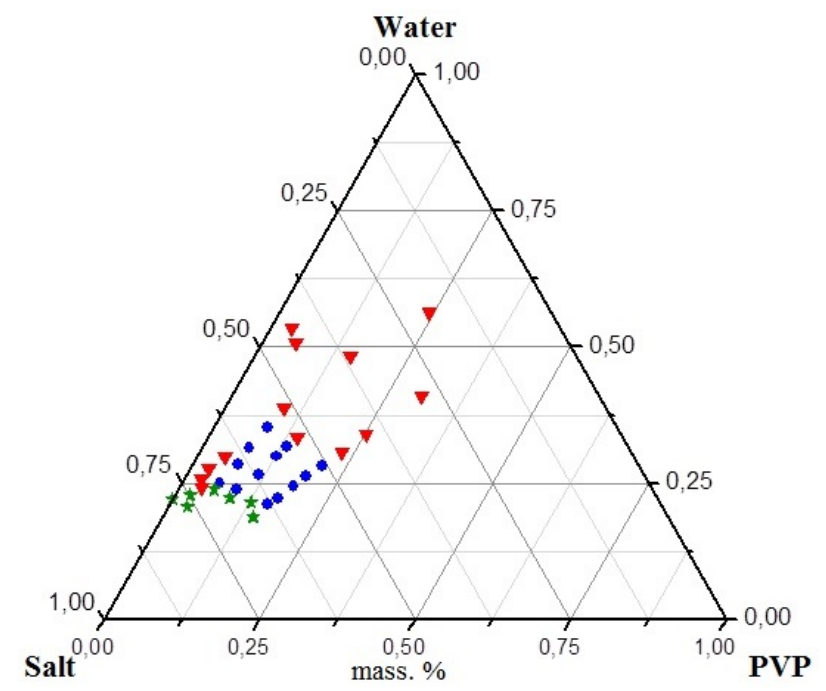

FIG. 8. Isothermal section of the phase state diagrams for the copper nitrate - polyvinylpyrrolidone - water system. The symbols are the same as in Fig. 7

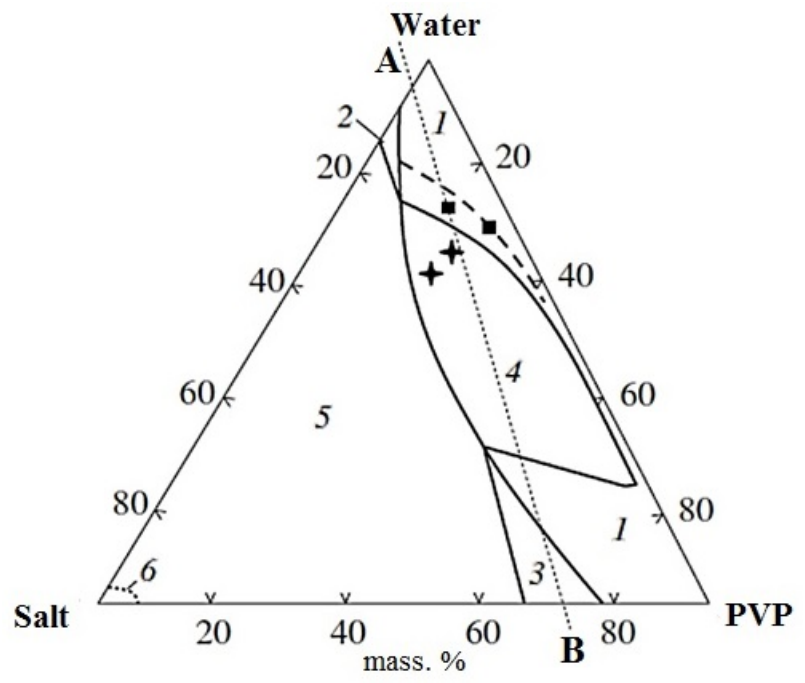

FIG. 9. The phase state diagram for the tetrahydrate ammonium heptamolybdate polyvinylpyrrolidone - water system. The explanations are given in the text

where the liquid and solid phases coexist. Unlike the previous diagram types where there is amorphous crystal immiscibility, we can see the area of amorphous liquid immiscibility in the system (4). The salt phase (6) coexists with two liquid phases in the area (5). The study of the temperature effect on the phase separation processes of this system showed that the amorphous immiscibility area expands by the temperature increase (in particular, at $70^{\circ} \mathrm{C}$ ). This is reflected as a dotted-line projection in the diagram (Fig. 9). At a lower temperature $\left(15^{\circ} \mathrm{C}\right)$, the samples whose compositions are marked with asterisks, by contrast, did not show liquid immiscibility. Fig. 10 shows the poly-thermal phase diagram section along the A-B line, it is clear that the complexity of this diagram is caused by the upper and lower critical immiscibility points. The ammonium heptamolybdate - PVA - water system is also characterized by liquid-phase immiscibility which manifests itself with temperature increase (Fig. 11).

It should also be noted that the formation of complexes or associates between the metal ions and the organic component can have a favorable effect on the solubility of salt components, thus expanding the area of homogeneity for the solutions [180-182]. Some well-known examples of these samples are glycerin and glycine complexes of transition metals, in particular copper. Table 1 gives data for comparing the strength of glycine and other transition metal complexes. The possibility to form associates between similar metal ions and polymer components expands the homogeneity area on the phase diagrams, as well as inhibits secretion and growth of phase non-homogeneities 


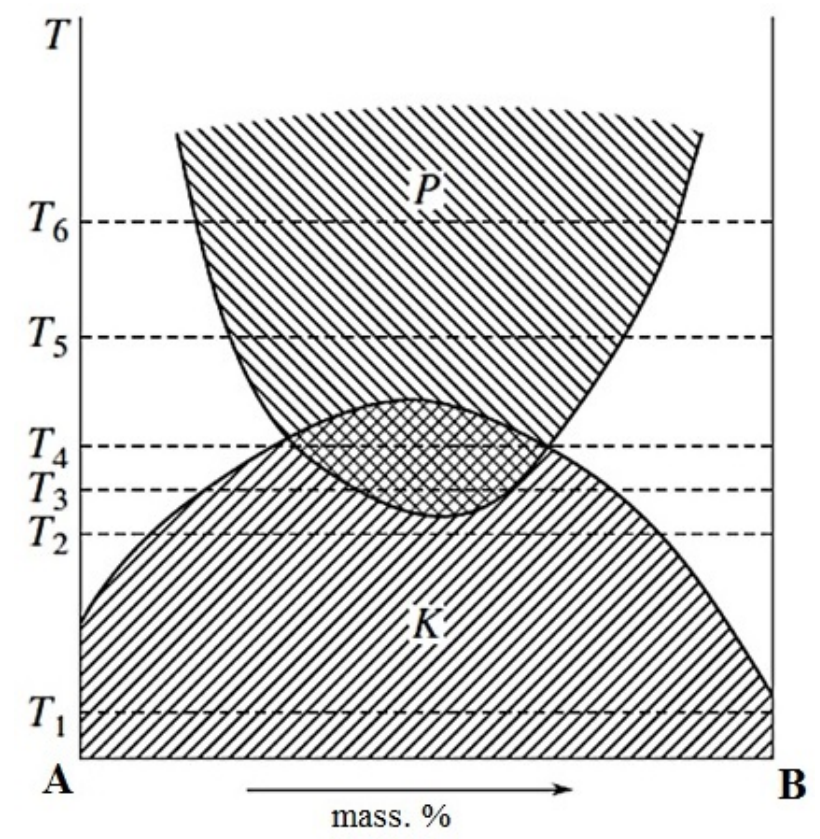

FIG. 10. Poly-thermal diagram section (Fig. 9). $\mathrm{K}-$ the area of salt crystallization; $\mathrm{P}-$ the area of liquid-phase (amorphous) immiscibility. Further explanations are given in the text

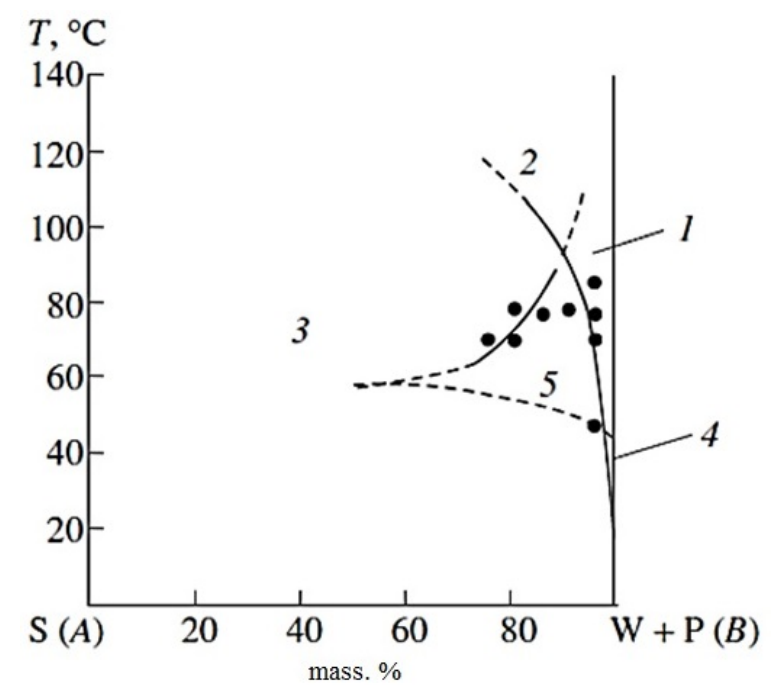

FIG. 11. Poly-thermal sectional phase-diagram fragment (Fig. 1) along the A-B line. The dots denote experimental points. 1 - Homogeneous solutions; 2, 4- area of coexistence of two liquid phases; 3 - the coexistence of liquids and crystals; 5 - the area of amorphous crystalline immiscibility

in the process of solvent removal. The literature has data for the transition metal complexation with water-soluble nonionic polymers; the information regarding the PVA is given in Table 2. The papers [180,181] studied the thermodynamics of polymer complexation, and their low molecular weight analogs, with metal cations and anionic forms including a multicharged metal (Mo) in some systems. In particular, it was found, as exemplified by the interaction of PVA, PVP, polyethylene glycol (PEG) with ions of cadmium(II) and copper(II), that PVP interacts the most actively with the divalent ions. This is shown for $\mathrm{Cd}^{2+}$ at higher negative values of the interaction enthalpy, the Gibbs energy and the complex formation constant. For $\mathrm{Cu}^{2+}$ ions, as compared to cadmium complexation, the constant is even higher; however, the energy factor does not contribute to spontaneous emergence of its complexes. Table 3 shows the significant role of the entropy factor in the complexation. The complexation is 
accompanied, in particular, by dehydration of ions and functional groups of organic compounds which act as ligands. Herewith, the water molecules released during dehydration gain translational mobility. Due to this, in particular, the system's entropy may increase. In [183], it was shown that water-soluble polymers of various origins can differently influence the water structure and the ability of ions to form the ion complexes (associates) with the polymer. The damaged structure of water in solutions of rather more hydrophobic PVA causes increased hydration interactions between the ions and water molecules. Stabilization of water structure in hydrophilic PVP solutions should determine greater development of polymer - ion solvation effects and the increase in the tendency for ion association or complexation with polymer molecules. The determining role of the above entropy factor was also confirmed by the example of the studied complex polyoxometalates, including a polymer component (PVA) [184]. The study of ammonium heptamolybdate-containing systems revealed that the low-molecular substance (ethylene glycol which can also be considered as a glycerin analogue), as compared to the high-molecular compounds of similar structure (PVA), is able to interact more actively with heptamolybdate (Table 3).

TABLE 1. The stability constants for complexes of heavy metals with organic ligands [185]

\begin{tabular}{|l|c|c|c|c|c|}
\hline \multirow{2}{*}{ Ligand } & \multicolumn{5}{|c|}{$\mathrm{IgKc}$} \\
\cline { 2 - 6 } & $\mathrm{Ni}^{2+}$ & $\mathrm{Zn}^{2+}$ & $\mathrm{Cd}^{2+}$ & $\mathrm{Cu}^{2+}$ & $\mathrm{Pb}^{2+}$ \\
\hline $\mathrm{NH}_{3}$ & 2.8 & 2.37 & 2.65 & 4.25 & \\
\hline Glutathione $\left(\mathrm{RS}^{1-}\right)$ & 4.0 & 5.0 & 6.16 & & \\
\hline Imidazole (=N) & 3.0 & 2.52 & 2.8 & & \\
\hline Acetate $\left(\mathrm{O}^{1-}\right)$ & 0.8 & 0.7 & 1.2 & & \\
\hline Glycine & & 5.52 & 4.8 & 8.62 & 5.47 \\
\hline Oxalate & & 4.68 & 4.0 & 6.19 & 4.0 \\
\hline OH & & 4.4 & 4.6 & 6.3 & 6.2 \\
\hline Carbonate & & 4.8 & 4.0 & 6.77 & 6.2 \\
\hline Humic acids (pH8) & & 5.3 & 5.0 & 5.0 & $5.3-8$ \\
\hline Surface particles (pH8) & & -3.6 & -3.7 & -1.8 & -1.7 \\
\hline
\end{tabular}

TABLE 2. Complexation constants and thermodynamic parameters of M(II) - PVA reactions [186]

\begin{tabular}{|c|c|c|c|c|c|c|}
\hline $\mathrm{M}(\mathrm{II})$ & $\lg \left(\mathrm{K}_{1}\right)$ & $\lg \left(\mathrm{K}_{2}\right)$ & $\lg (\mathrm{K})$ & \multicolumn{3}{|c|}{$\Delta \mathrm{G}, \mathrm{kcal} / \mathrm{mol}$} \\
\hline & & & & $-\Delta \mathrm{G}_{1}$ & $-\Delta \mathrm{G}_{2}$ & $-\Delta \mathrm{G}_{\text {aver. }}$ \\
\hline $\mathrm{Co}$ & 5.67 & 5.32 & 11.06 & 8.18 & 6.42 & 16.0 \\
\hline $\mathrm{Ni}$ & 6.21 & 5.60 & 11.82 & 8.36 & 7.90 & 16.0 \\
\hline $\mathrm{Cu}$ & 8.07 & 7.86 & 15.93 & 11.53 & 11.10 & 22.52 \\
\hline $\mathrm{Zn}$ & 6.94 & 6.63 & 13.57 & 10.14 & 9.52 & 19.23 \\
\hline
\end{tabular}

One study [187] suggested a structure model for complexes of oxygen-containing ions with polymers (Fig. 12). As shown in $[182,186]$, the interaction of different ions with the polymer macromolecules, in view of significant influence of the entropy factor as well, is of the specific features as manifested in heterogeneous ion distribution in the solution, both between the macromolecules therein and within a single macromolecule joined in the interaction. The interconnection of ions and the polymer is facilitated on the chain section which is adjacent to the previously attached ion. In the case of polyoxometalate ions, this leads to induced-rigidity portions of the polymer chains, while the solutions, which become similar to liquid crystals, gain mesomorphic properties [187, 188]. The films derived from these solutions indicate a coaxial orientation for the rigid fragments of the polymer-saline associates (Fig. 13); in this case, apparently, they are perpendicular to the film surfaces. This is shown by a specific kind of x-ray diffraction patterns of the films $[187,189]$. When deriving oxide materials from textured films, you can expect 
TABLE 3. Thermodynamic parameters of $\mathrm{Cd}^{2+}$ and $\mathrm{Cu}^{2+}$ ion complexation with PVA, PEG, PVP at room temperature [181]

\begin{tabular}{|c|c|c|c|c|}
\hline \multirow{2}{*}{ System } & \multirow{2}{*}{$\mathrm{K}_{p}$} & $\Delta \mathrm{G}_{\text {compl }}^{0}$ & $\Delta \mathrm{H}_{\text {compl }}^{0}$ & $\mathrm{~T}_{\Delta} \mathrm{S}_{\text {compl }}^{0}$ \\
\cline { 3 - 5 } & & \multicolumn{3}{|c|}{$\mathrm{kJ} / \mathrm{mol}$} \\
\hline $\mathrm{Cd}^{2+}-\mathrm{PVA}$ & $2.3 \cdot 10^{4}$ & -24.9 & -0.25 & 24.6 \\
\hline $\mathrm{Cd}^{2+}-\mathrm{PEG}$ & $2.2 \cdot 10^{8}$ & -47.6 & -0.46 & 46.9 \\
\hline $\mathrm{Cd}^{2+}-\mathrm{PVP}$ & $9.1 \cdot 10^{4}$ & -28.3 & -0.75 & 27.5 \\
\hline $\mathrm{Cu}^{2+}-\mathrm{PVA}, \mathrm{PEG}$ & $3.1 \cdot 10^{6}$ & -37.1 & 24.0 & 61.1 \\
\hline
\end{tabular}

at least partial texture inheritance by the complex oxide coatings on the media [163]. The issues regarding the pyrolytic production of textured coatings are of practical interest. The phenomenon of directional salt component crystallization is evident in the polymer-saline compositions (PSC) on single crystal substrates in those cases where crystallization is not suppressed (Fig. 14). It is practically possible to produce textured oxide films from such precursors, (Fig. 15), for example, the superconducting ones [163], in which the crystallites have a preferential orientation.

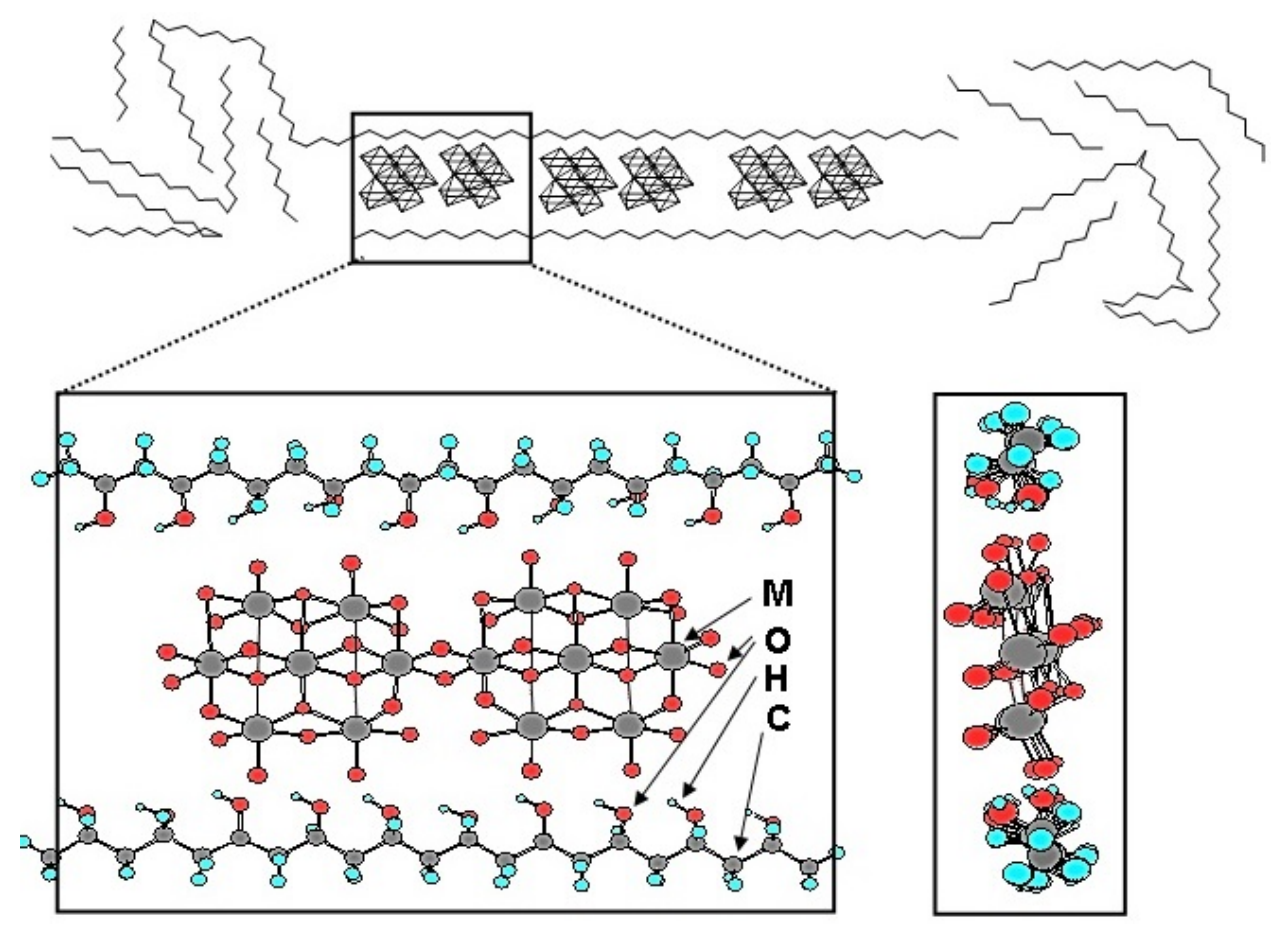

FIG. 12. Polymer-saline ammonium heptamolybdate and polyvinyl alcohol complex structure $\mathrm{M}=\mathrm{Mo}$

When exposed to light, the precursors comprising ions of such metals as vanadium, tungsten, molybdenum allow for partial reduction of metals due to photochemical reactions of the electron transfer from the polymer component to the oxygen-containing ion. Any earlier associates remain unchanged; however, the formation of charge-transfer complexes may affect the type of the phase diagram, thus expanding in particular the homogeneity area (Figs. 1,4) due to the better solubility of such complexes. Incidentally, such PSC may be used as catalytic materials for photochemical processes under mild conditions [190,191]: e.g. the sulfide oxidation to polysulfide, selective oxidation of $\alpha$-pinene to verbenol or verbenone etc. The flow of autocatalytic oscillatory reactions discovered in PSC themselves [192,193] contributes to this as well. Polymer film compositions which include partially recovered vanadium, molybdenum and tungsten ions have been proposed for use as membranes of ionselective electrodes which are sensitive to the aforementioned ion concentrations in the solutions studied [179,194]. 


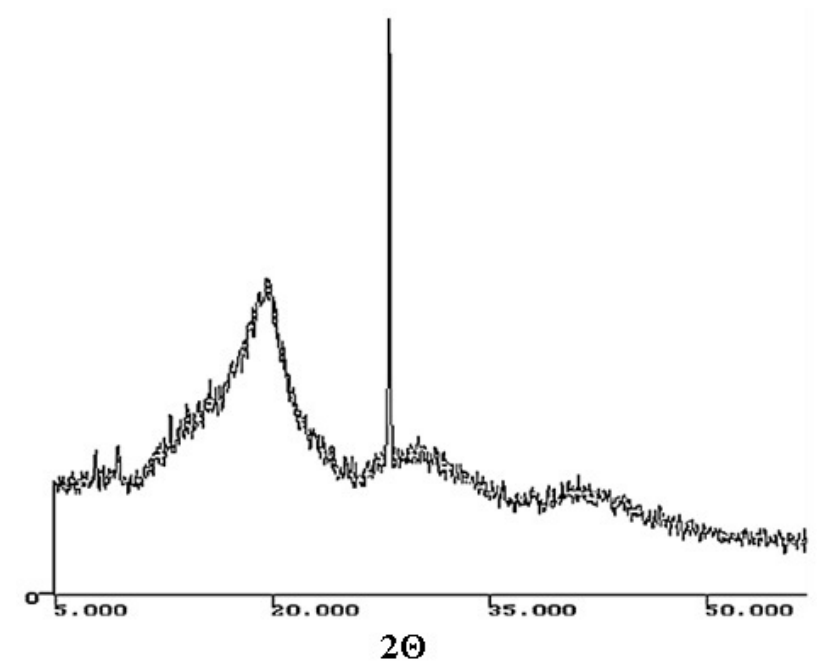

FIG. 13. X-ray diffraction pattern (CuK-radiation) of the polymer-saline ammonium tungstate PVA ( 2 and $10 \% \mathrm{w}$, in initial solution respectively) film composition

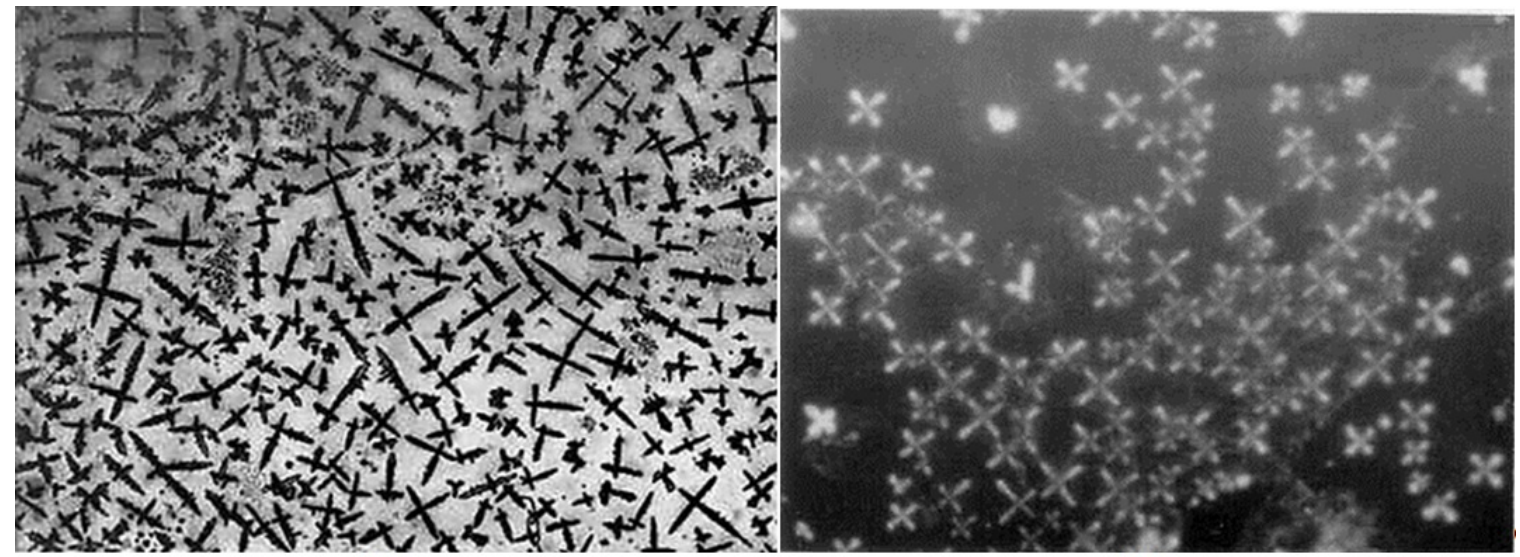

(a) (b)

FIG. 14. Salt component ( $\mathrm{Y}, \mathrm{Ba}, \mathrm{Cu}$ nitrates) crystallization in the PVA films to derive $\mathrm{YBa}_{2} \mathrm{Cu}_{3} \mathrm{O}_{7-\delta}(\mathrm{YBC}) \mathbf{a}-$ on the glass $(200 \times) ; \mathbf{b}$ - on the single crystal MgO substrate $(100 \mathrm{x})$. The least soluble barium nitrate crystallizes prevalently, then, crystallites grow from the primary crystal faces

To conclude this Section, we should mention another option to produce homogeneous precursors in those cases where the oxides are composed of ions of vanadium, molybdenum, tungsten [195-198] and metals with similar chemical properties. There is precipitation when introducing the ions of most alkaline earth, rare earth, and transition metals into such metallic saline solutions to produce the respective complex oxides. The precipitate contents of the low-solubility compounds are variable and depend on several factors: temperature, concentration, acidity, the mixing sequence of initial solutions, and in some cases, even on the mixing intensity. This makes it difficult to produce a complex oxide a strictly defined stoichiometry. The mixing of solutions, with a polymeric component available, allows production of a stable gel with a given composition [199,200] due to the fact that the reagents are pre-connected with a polymer into the complexes. Then, a three-dimensional spatial grid which includes the corresponding ions as uniformly distributed by volume is formed in the gel. It is possible to remove water from such gels without breaking their homogeneity, and to carry out pyrolytic synthesis of complex oxide, including on the media, as implemented in the course of producing the lanthanum-cesium vanadate, the soot oxidation catalyst [201]. The alkali metal compounds (in this case, the cesium nitrate) participate scarcely in complexation, and are included in the precursor as the dispersed-phase components of the polymer-salt matrix. The systems described can be represented by diagrams of the gel stability to spatial phase separation, as similar visually to the phase diagrams (Fig. 16) having a lower critical immiscibility point. 


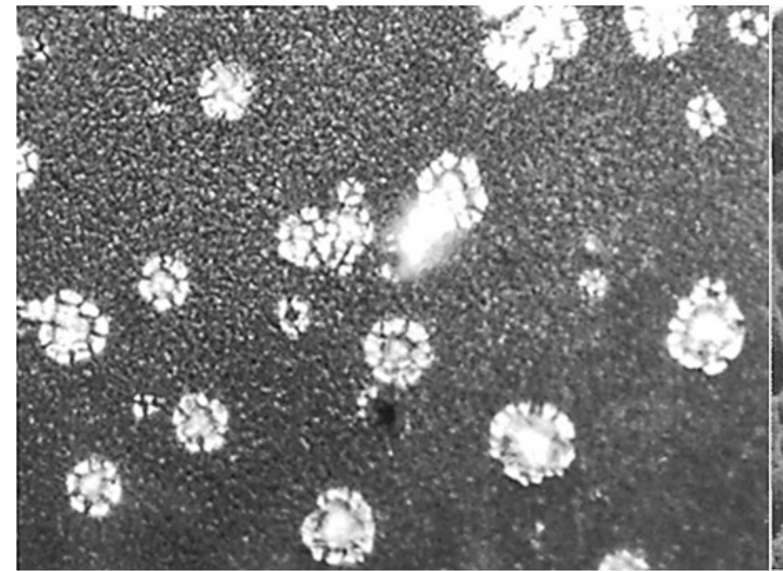

(a)

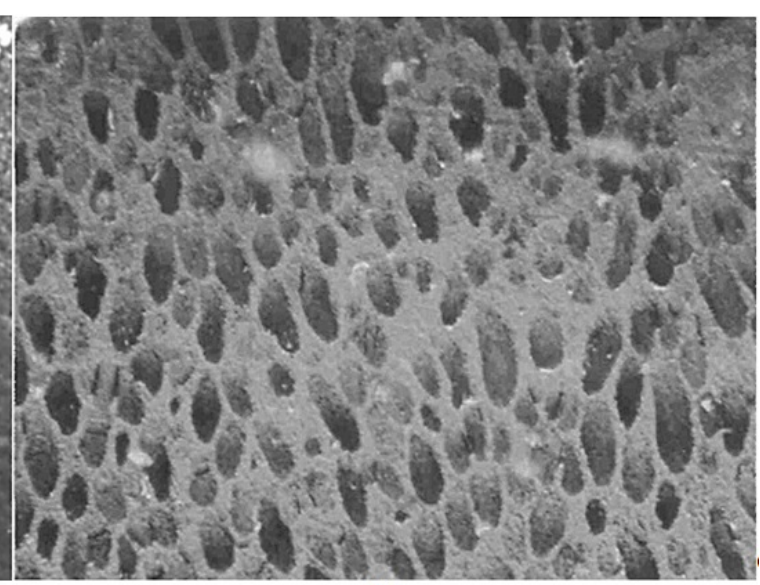

(b)

FIG. 15. Stages of the oriented YBC film formation of the polymer-saline composition: a $500 \times ; \mathbf{b}-1000 \times$

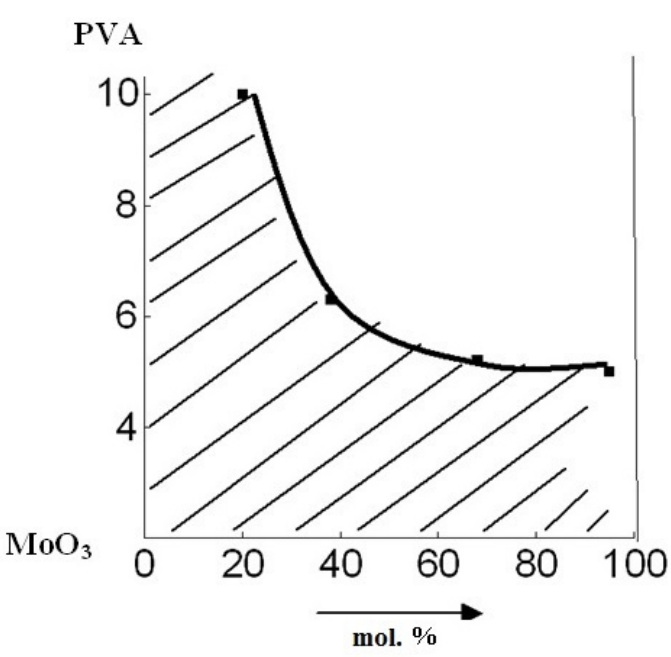

(a)

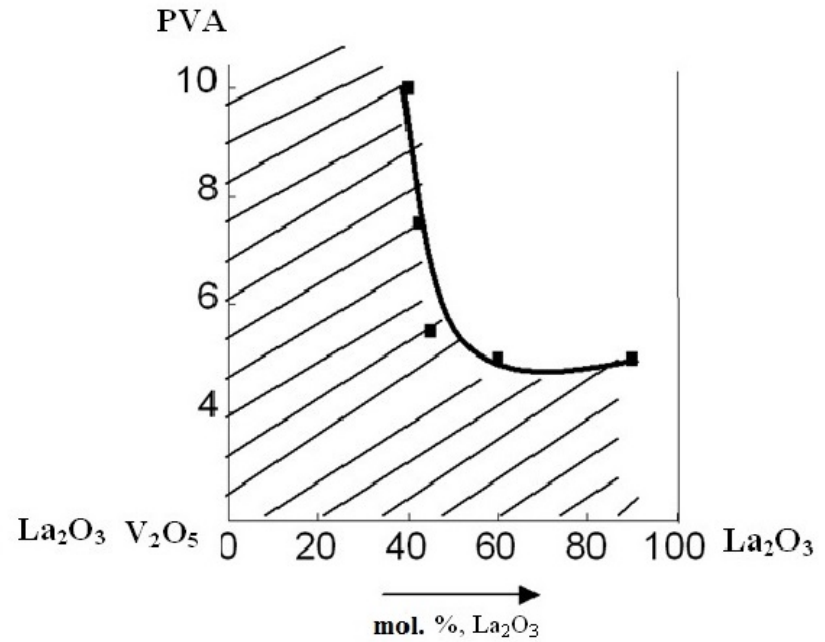

(b)

FIG. 16. Stability diagrams for polymer-saline gels with a total salt content of 0.35 mass $\%$ in the ammonium heptamolybdate - lanthanum (III) nitrate (a) and ammonium metavanadate - lanthanum (III) nitrate (b) systems. PVA - polyvinyl alcohol concentration in mass \%; $\mathrm{MoO}_{3}\left(\mathrm{~V}_{2} \mathrm{O}_{5}\right)-\mathrm{La}_{2} \mathrm{O}_{3}$ content in mol. \%. The gel separation area is shaded

It should be noted that when there are acidic reactions in the solutions, the anionic forms of oxygen-containing ions of molybdenum, tungsten, and vanadium are able to transform into cationic molybdenyl- and vanadyl-type forms. In the case of tungsten, especially without any organic component, there may be precipitation of the socalled tungstic acidic mixture. The precursor's acidity has an effect on the results of pyrolytic synthesis of these metallic oxides, which was shown, in particular, in [198].

\section{Features of precursor combustion and oxide material synthesis}

When producing oxide materials, the precursor combustion is characterized by a number of parameters such as the burning rate, pyrolysis localization in the volume of the reaction medium, its temperature, the composition and temperature of the gases released, etc. These parameters are determined by the nature of components used in the original compositions, the ratio of the oxidant (mainly, the nitrate part of the system) and reductant (the organic component). The nitrate ions are the oxidizing agent as part of homogeneous organic-inorganic compositions. The thermal nitrate decomposition itself is accompanied by release of gaseous products which have oxidizing properties (oxygen, nitrogen oxides), herewith, an active oxidizing agent may be the atomic oxygen at the time of its emission 
(nascent state). On the contrary, during thermal degradation, the salts of organic acids (formates, acetates, etc.) create a reducing environment due to the availability of such gases as carbon mono- and dioxide and, sometimes, hydrogen. The organic salt decomposition may generate carbon; the degradation of these salts may result in reduced forms of metals such as copper $-\mathrm{Cu}^{+}, \mathrm{Cu}^{0}$. Considering that it is possible to create mixed precursors comprising salts of different origin, this aspect can be used to regulate the intensity of pyrolysis, production of materials which include low-oxidized metals. Nitrates of various metal groups undergo thermal decomposition at significantly different temperatures. In addition, degradation can occur stepwise. Below, we address such a case exemplified by the salt destruction when producing $\mathrm{YBa}_{2} \mathrm{Cu}_{3} \mathrm{O}_{7-\delta}(\mathrm{YBC})$.

$$
\begin{gathered}
\mathrm{Ba}\left(\mathrm{NO}_{3}\right)_{2}=\mathrm{Ba}\left(\mathrm{NO}_{2}\right)_{2}+\mathrm{O}_{2} \\
\mathrm{Ba}\left(\mathrm{NO}_{2}\right)_{2}=\mathrm{BaO}+\mathrm{NO}+\mathrm{NO}_{2} \\
\mathrm{Y}\left(\mathrm{NO}_{3}\right)_{3}=\mathrm{YONO}_{3}+2 \mathrm{NO}_{2}+1 / 2 \mathrm{O}_{2} \\
2 \mathrm{YONO}_{3}=\mathrm{Y}_{2} \mathrm{O}_{3}+2 \mathrm{NO}_{2}+1 / 2 \mathrm{O}_{2} \\
\mathrm{Cu}\left(\mathrm{NO}_{3}\right)_{2}=\mathrm{CuO}+2 \mathrm{NO}_{2}+1 / 2 \mathrm{O}_{2}
\end{gathered}
$$

It should be noted that the step degradation may lead to broken homogeneity in the synthesis products due to the growing granules of the newly formed intermediate oxide phases. Stepwise salt destruction is usually manifested in the complex oxide production by thermal salt mixture decomposition which is not accompanied by the use of organic components. The thermal destruction temperatures vary greatly for nitrates of different metals, for example, these temperatures are ranged 100 to $800^{\circ} \mathrm{C}$ when producing YBC. Part of the nitrates, the salts of alkaline earth and some transition metals, are decomposed through a melting stage. The resulting melts are corrosive and can interact actively with the materials of reaction vessels.

Application of nitrate-organic precursors enables one to solve most of these problems. First of all, the exothermic pyrolysis temperature of the system decreases upon introduction of organic components into the mixture of metal nitrates (Fig. 17). In most cases, the combustion itself is reflected in the thermal analysis results as a single intensive exothermic effect. Experiments show that, other things being the same, the maximum combustion rates and the developing temperatures are usually achieved in the nitrate precursors comprising organic components with nitrogen atoms in the oxidation degree of $3-$, as entering into an energetic reaction (up to explosion) of comproportionation with nitrate nitrogen $(5+)$ atoms. These (nitrogen $(3-))$ include, for example, polyvinylpyrrolidone, glycine. Therefore, these substances can be considered as analogs in a sense, in terms of implementation of the pyrolytic oxide synthesis. Polyvinyl alcohol, ethylene glycol, glycerol consisting of a carbon skeleton with hydroxyl groups attached act as another precursor group of similar interaction. The thermograms (Figs. 17,18) $[165,169]$ show that in the process of heating, the salt mixture decomposition is accompanied by a number of endothermic effects of the stepwise decomposition of the respective nitrates, whereas with a polymer available, the sign of thermal effects changes, the decomposition temperature decreases due to the combustion effect, the sample mass stabilizes at a substantially lower temperature.

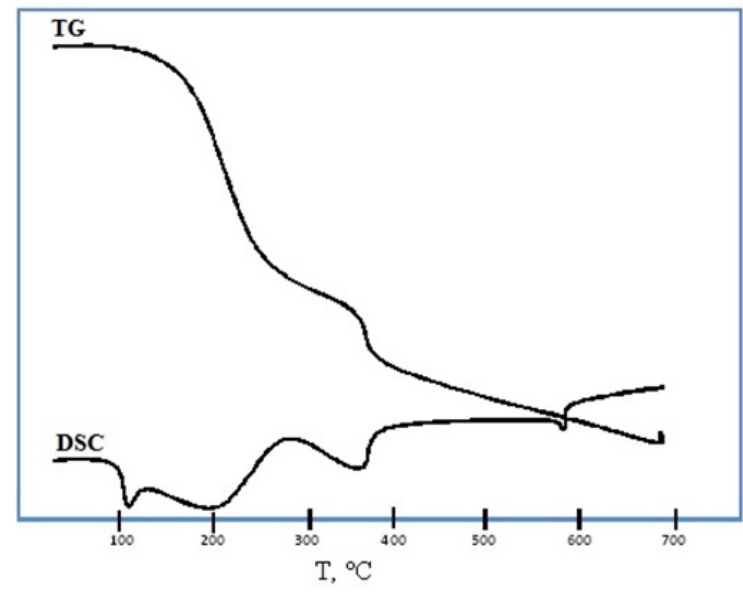

(a)

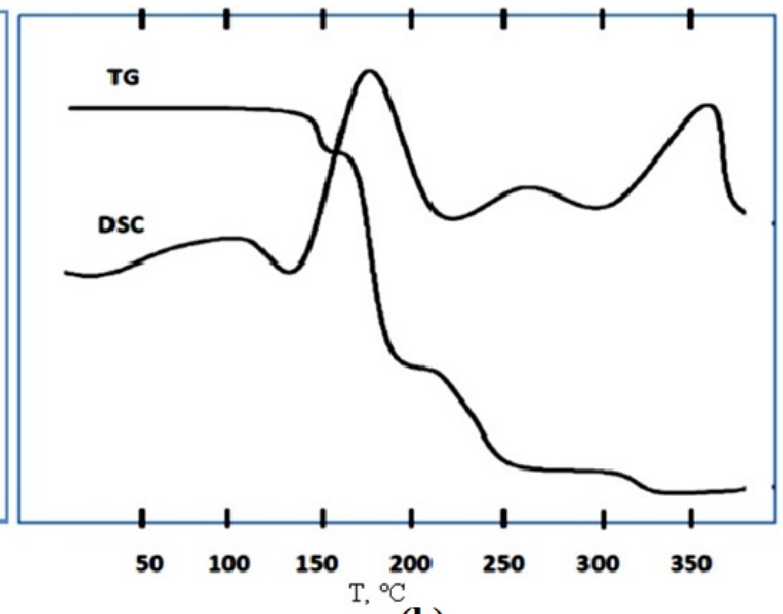

(b)

FIG. 17. Thermograms (D-1500Q derivatograph) of reaction mixtures; a - cobalt, lanthanum, strontium nitrates; $\mathbf{b}$ - the same with PVA introduced 
Calculation of precursor combustion reactions is usually carried out based on the condition of carbon dioxide, water and molecular nitrogen release as evolved gaseous products (see for instance [94, 112, 118, 202]). The defined ratio between the nitrate part of the system and the organic component is considered stoichiometric, which corresponds to the imputation rate $\varphi=1$. When $\varphi<1$, the reaction system lacks the organic component, and when $\varphi>1$, there is an excess which may ultimately require additional oxidation, for example, by atmospheric oxygen. Oxidants, in particular, additional oxygen may be required and should be taken into account when the metal components are available low valent compounds in the salt compositions, e.g., $\mathrm{Co}^{2+}, \mathrm{Mn}^{2+}$ rather than characteristic $(3+$ and $4+)$ for many oxides. In some cases, where there are stably oxidized metallic components, a simplified stoichiometry calculation scheme can be used. This should take into account a free nitric acid as well, when they use acid solutions with its excess:

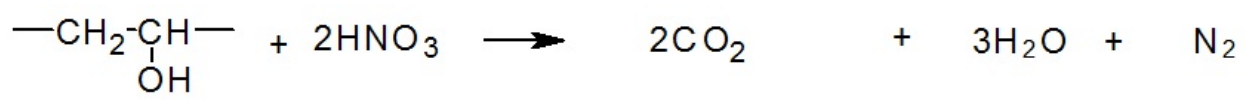

It can be assumed that pyrolysis processes occur the most intensively in various systems if the ratio is $\varphi=1$. In this respect, the experiments on the measurement of the real temperature-time combustion parameters are deemed quite interesting. Such experiments have been implemented, in particular, by synthesis of calcium zirconate $\mathrm{CaZrO}_{3}$ $[112,118]$ as a practically important material for producing dielectric and refractory ceramics, a component of the photocatalytic and luminescent systems, solid electrolytes with different conductivity. Calcium metazirconate was synthesized by the SCS method [203], using various organic reagents such as $\beta$-alanine [204], citric acid [205,206] or citric acid with urea [207], glycine $[138,208]$ for the combustion reaction. To determine the combustion parameters in $[112,118]$, the synthesis was carried out in glycine-nitrate systems. To achieve reproducible results, they provided the same geometry of the reaction vessel and the same type of solvent evaporation. The synthesis temperature of $\mathrm{CaZrO}_{3}$ was recorded using two thermocouples with a measurement period of $0.12-0.2 \mathrm{~s}$. The temperature of the gases released was measured by an infrared pyrometer. The gas composition was determined by a gas analyzer. Depending on the $\varphi$-value, there were three types of pyrolytic processes observed. When $\varphi<0.8$ (Fig. 19), the pyrolysis occurred in amorphization (smoldering combustion), the reaction was gradually spreading in the reactant environment as a narrow combustion front occurring at relatively low temperature and gentle temperature profile. When the $\varphi$-values were ranged $0.8-1.1$ (overall combustion), the process time was minimal (Fig. 19), the combustion spread quickly over the whole reaction volume. When $\varphi \geq 1.2$, the combustion occurred in a manner similar to that of SHS. The reaction medium was highly heated some time after the combustion front had occurred. The maximum process temperature did not meet the stoichiometric ratio, and was achieved at $\varphi=1.3$ (Fig. 20). At low $\varphi$-values, significant amounts of nitrogen oxides were released, as calcium and zirconyl nitrates could decompose thermally like salts. At high $\varphi$-values, there was increased content of carbon monoxide in the gaseous environment. The absence of the area where combustion occurred with no release of nitrogen oxides and carbon monoxide suggests that the actual processes differ from the design scheme. It must be assumed that divergence of the processes from theoretical ideas will increase with local inhomogeneities appearing in the overall component distribution. The use of PVP precursors as an organic component can lead to the formation of another redox interaction product when an excess of nitrogen, being initially oxidized as 3-, is incompletely oxidized by the nitrogen nitrate and forms a lower nitrogen oxide. The data from GC-MS analysis of the gas composition during air pyrolysis of the film PVP composition with $\mathrm{Ag}, \mathrm{La}, \mathrm{Mn}$ nitrates showed that after removal of water, there were two stages of $\mathrm{N}_{2} \mathrm{O}$ release, followed by significant $\mathrm{CO}_{2}$ emission with impurities of organic substances. Against this background, there were emissions of certain amounts of $\mathrm{NO}$ and $\mathrm{NO}_{2}$ (Fig. 21; the thermogram is shown in Fig. 18). In some cases, the oxide SCS products can contain the residual carbon coloring white materials with a gray or brownish tint.

In the thermal analysis of the oxide SCS production processes, the thermograms display, in addition to the main exothermic effect, the availability of at least another one being less intensive (Fig. 17,18). The origin of this maximum can be explained by the burnout of residual carbon. At a relatively low temperature in the additional thermal treatment of the SCS products, the carbon is almost completely removed. Thus, the carbon content did not exceed thousandths of a percent in the $\mathrm{YBa}_{2} \mathrm{Cu}_{3} \mathrm{O}_{7-\delta}$ samples produced by the SCS method in the metallic nitrates - PVA system where its presence is critical [153]. The carbon oxidation by oxygen is accelerated during additional heat treatment of the materials produced, and facilitated with catalytic properties of the oxide systems. Such properties, to different extents, are characteristic for many oxides, including $\mathrm{YBa}_{2} \mathrm{Cu}_{3} \mathrm{O}_{7-\delta}$, which are composed of transition metals [202]. It is especially typical for oxides based on metals which change rather easily the oxidation degree and are capable to form compounds with low metal - oxygen binding energy, such as $\mathrm{Cu}, \mathrm{Mn}, \mathrm{Co}$, etc. The carbon is also oxidized effectively in the oxides, including lanthanum vanadates [201] 


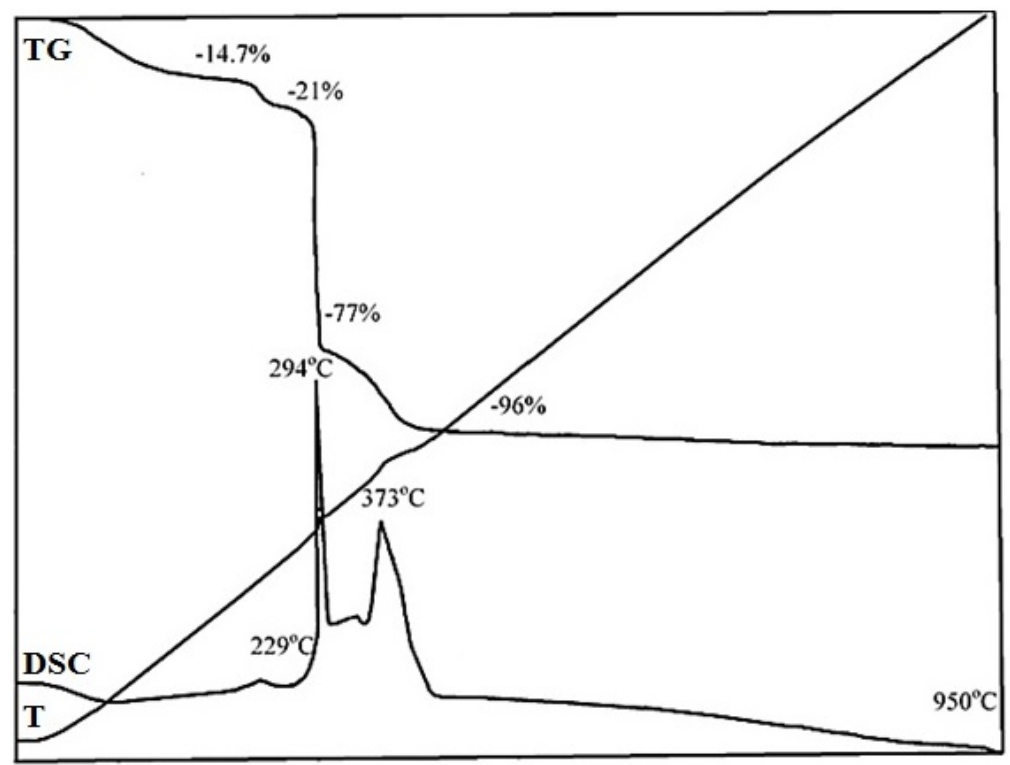

FIG. 18. Thermogram of the reaction mixture (polymer saline composition) containing the nitrates of lanthanum (III), silver (I) manganese (II) and PVP, the heating rate is $10^{\circ} \mathrm{C} / \mathrm{min}$. T is the temperature

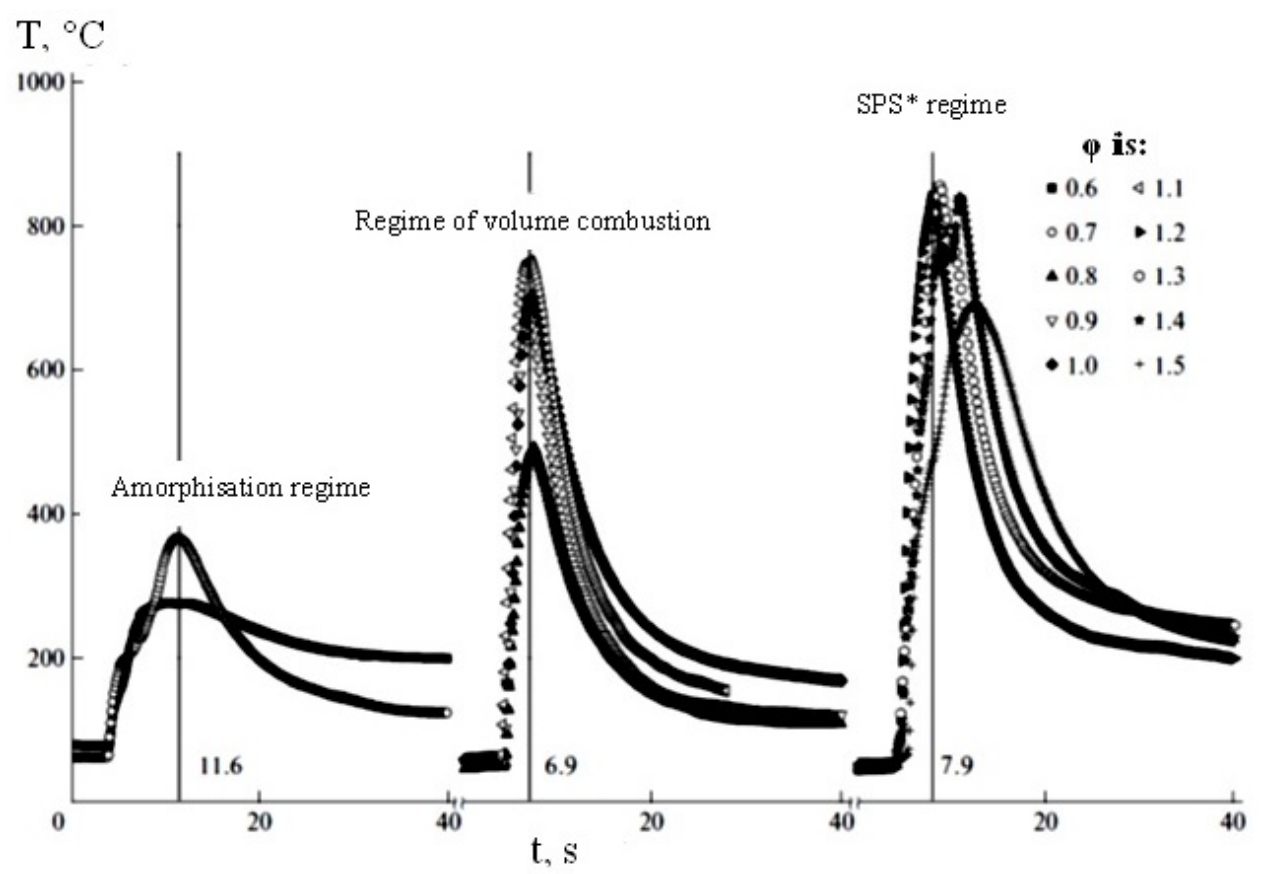

FIG. 19. Temperature combustion profiles in the $\mathrm{CaZrO}_{3}$ synthesis 


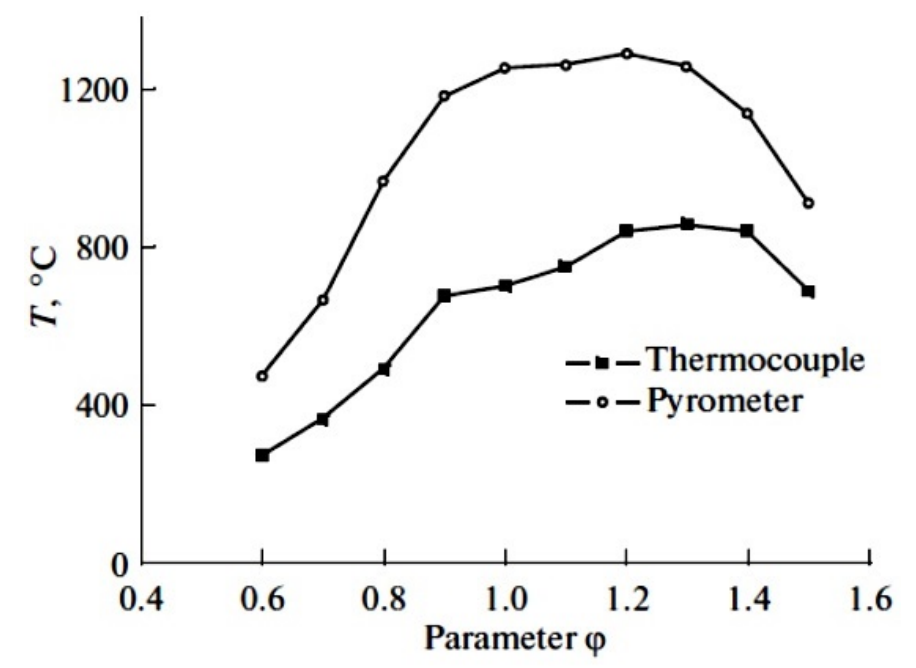

FIG. 20. Maximum combustion temperatures attained as depending on the $\varphi$-parameter

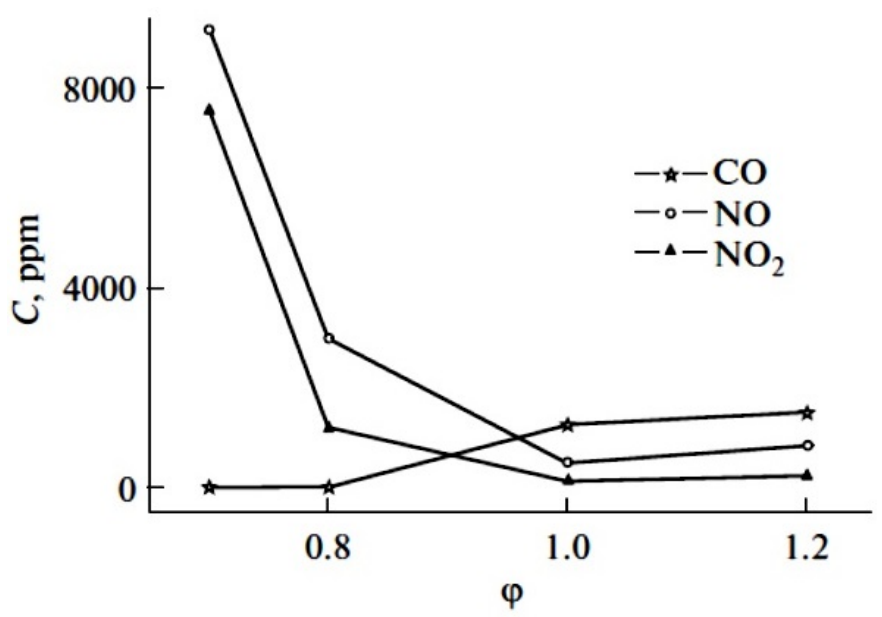

FIG. 21. $\mathrm{CO}, \mathrm{NO}, \mathrm{NO}_{2}$ concentration in combustion products

doped with alkali metal ions where, as expected, the intermediate unstable carbonate complexes are formed. In general, the catalytic processes have a sufficiently strong effect on the precursor production and pyrolysis [202]. Some compounds with labile-oxidized metals affect organic compounds at the stage of preparing solutions. Thus, in concentrated solutions of the moderately heated iron (III) nitrate and PVA, the intensive redox reaction starts with gassing and self-heating. In some cases, a catalytic effect is evident after the production of film precursors. It is typical, for example, for compounds of molybdenum and tungsten, especially in an acidic environment. When poorly heated and exposed to light, there are reactions with partial metal reduction to the oxidation degree of $(5+)$, the appearance of blue color, and, sometimes, of the spongy film structure due to gases released. During combustion of the compositions, the catalytic properties of their constituent compounds are achieved.

Special studies have shown that the combustion rate of the PVA-based film precursors depends essentially on the possibility to change the oxidation degree of the metal components, and the availability of catalytic properties in the intermediate phases and the synthesis products. The precursors containing nitrates of stably oxidized alkaline and rare earth elements combust slowly and unstably, there is no intense pyrolysis [202] (Tables 4, 5). More stable and high-rate combustion is characteristic for the films containing the transition metallic nitrates and silver (Table 5). The factors decreasing the combustion rate may be the existence of crystalline hydrates formed by nitrates. The combustion rate may enhance the catalytic properties, which is clearly exemplified by the systems in which the respective complex oxides are formed. The catalytic action of metallic silver which appears as nanoparticles during combustion may result from the ability to change its oxidation, $\mathrm{Ag}^{0} \leftrightarrow \mathrm{Ag}^{1+}$. It can be 
assumed that the paramount importance to enable the catalytic effect on precursors at different synthesis stages is a result of the Red/Ox potentials for the respective ions which are given in Table 4 to illustrate the above.

TABLE 4. Oxidation potential of reactions and the catalytic effect of inorganic ions

\begin{tabular}{|c|l|c|c|l|c|}
\hline No & Reaction & E, V & No & Reaction & E, V \\
\hline 1 & $\mathrm{Fe}^{3+}+\bar{e} \rightarrow \mathrm{Fe}^{2+}$ & $+0.771^{*}$ & 10 & $\mathrm{MoO}_{2}^{2+}+\bar{e} \rightarrow \mathrm{MoO}_{2}^{+}$ & $+0.48^{* *}$ \\
\hline 2 & $\mathrm{Mn}^{3+}+\bar{e} \rightarrow \mathrm{Mn}^{2+}$ & $+1.51^{* * *}$ & 11 & $\mathrm{WO}_{4}^{2-}+4 \mathrm{H}_{2} \mathrm{O}+6 \bar{e} \rightarrow \mathrm{W}^{0}+8 \mathrm{OH}^{-}$ & -1.05 \\
\hline 3 & $\mathrm{Co}^{3+}+\bar{e} \rightarrow \mathrm{Co}^{2+}$ & $+1.95^{* * *}$ & 12 & $\mathrm{WO}_{4}^{2-}+8 \mathrm{H}^{+}+6 \bar{e} \rightarrow \mathrm{W}^{0}+4 \mathrm{H}_{2} \mathrm{O}$ & +0.05 \\
\hline 4 & $\mathrm{Co}^{2+}+2 \bar{e} \rightarrow \mathrm{Co}^{0}$ & 13 & $\mathrm{Sr}^{2+}+2 \bar{e} \rightarrow \mathrm{Sr}^{0}$ & -2.89 \\
\hline 5 & $\mathrm{Cu}^{2+}+\bar{e} \rightarrow \mathrm{Cu}^{+}$ & 14 & $\mathrm{La}^{3+}+3 \bar{e} \rightarrow \mathrm{La}^{0}$ & -2.52 \\
\hline 6 & $\mathrm{Cu}^{2+}+2 \bar{e} \rightarrow \mathrm{Cu}^{0}$ & 15 & $\mathrm{NO}_{3}^{-}+2 \mathrm{H}^{+}+\bar{e} \rightarrow \mathrm{NO}_{2}+\mathrm{H}_{2} \mathrm{O}$ & +0.80 \\
\hline 7 & $\mathrm{Cu}^{+}+\bar{e} \rightarrow \mathrm{Cu}^{0}$ & +0.159 & 16 & $\mathrm{NO}_{3}^{-}+4 \mathrm{H}^{+}+3 \bar{e} \rightarrow \mathrm{NO}_{2}+2 \mathrm{H}_{2} \mathrm{O}$ & +0.96 \\
\hline 8 & $\mathrm{Cr}^{3+}+\bar{e} \rightarrow \mathrm{Cr}^{2+}$ & +0.531 & 17 & $\mathrm{NO}_{3}^{-}+2 \mathrm{H}_{2} \mathrm{O}+3 \bar{e} \rightarrow \mathrm{NO}^{+}+4 \mathrm{OH}^{-}$ & -0.14 \\
\hline 9 & $\mathrm{Ag}^{+}+\bar{e} \rightarrow \mathrm{Ag}^{0}$ & -0.41 & 18 & $2 \mathrm{NO}_{3}^{-}+12 \mathrm{H}^{+}+10 \bar{e} \rightarrow \mathrm{N}_{2}+6 \mathrm{H}_{2} \mathrm{O}$ & +0.73 \\
\hline
\end{tabular}

*The catalytic effect is manifested directly in solutions;

$* *$ the effect begins to reveal in films;

$* * *$ the catalytic effect during pyrolysis.

TABLE 5. Combustion rate of PVA-based compositions

\begin{tabular}{|c|c|c|}
\hline No & Saline constituents of the composition & Combustion rate, cm.min \\
\hline 1 & Cobalt nitrate & $3-4$ \\
\hline 2 & Strontium nitrate & $3-5$ \\
\hline 3 & Lanthanum nitrate & $2-4 * *$ \\
\hline 4 & Manganese nitrate & $5-7$ \\
\hline 5 & Silver nitrate & $10-15$ \\
\hline 6 & Strontium nitrate and cobalt nitrate $\left(\mathrm{SrCoO}_{x}\right)^{*}$ & $11-13$ \\
\hline 7 & Lanthanum nitrate and cobalt nitrate $\left(\mathrm{LaCoO}_{3 \pm y}\right)^{*}$ & $14-18$ \\
\hline 8 & Lanthanum nitrate and manganese nitrate $\left(\mathrm{LaMnO}_{3 \pm y}\right)^{*}$ & $13-16$ \\
\hline 9 & Lanthanum nitrate, silver nitrate, and manganese nitrate & $15-20$ \\
\hline 10 & Silver nitrate and manganese nitrate $\left(\mathrm{AgMn}_{2} \mathrm{O}_{4}\right)^{*}$ & $30-40$ \\
\hline
\end{tabular}

*The synthesized oxide composition

**Unstable combustion

The basic mechanisms of pyrolytic oxide synthesis reveal in the thermochemical processes in the reactors where the solutions of organic-inorganic compositions are sprayed in a heated zone (spray pyrolysis). The positive effect of the available organic component also manifests in this case, since the fractional component crystallization, as well as stepwise thermal destruction, may occur in the pure salt mixtures, starting with the least soluble component. Ceramic oxide coatings are produced similarly, when the solutions are sprayed in doses on a heated media [169]. In addition, the polymer component provides for the formation of the initial film, which is then pyrolized, on the surface of the media. 
Studies of polymer-salt compositions (PSC) revealed a phenomenon that can significantly affect the results of the oxide material synthesis, the effect of thermochemical precursor charge generation [209]. Initially, this phenomenon was explored in polymer-saline, primarily PVA-based films by heating them below the initial combustion temperature [209,210]. A clear demonstration of charges in the films which were homoelectrets in that case, i.e. the two of their sides had the charge of the same polarity, represented an experiment where two samples were suspended parallel to each other and repulsed mutually and intensely, along with their deformation (bend), when heated. Placing the film between two electrodes which created a DC electric field, they managed to identify the film polarities which could vary depending on the composition. The measurement of potentials generated in the films gave a rather substantial charge density, around $1.7 \cdot 10^{-6} \mathrm{C} / \mathrm{cm}^{2}$. The charges existed steadily in the samples. During polarization by constant field based on salt-doped PVA films, they produced chemoheteroelectrets. The origin of charges can be attributed to a number of reasons. One of the main reasons is, in particular, the possibility of emission of volatile substances from the film by heating, which are composed of charged particles able to carry off the electrons or, on the contrary, have a positive charge by transferring an electron to the film. Such particles may be considered to be the ammonium molecules if the films include any salts of ammonium, water, $\mathrm{H}_{2} \mathrm{O}(-)$, nitrogen oxide $(\mathrm{NO}+)$, carbon dioxide, etc. Inter alia, the possibility of formation of particles with the "sticking" $\mathrm{CO}_{3}(-)$ electron cannot be ruled out $[210,211]$. Therefore, the film charge depends on the nature of the outbound charged particles in each case, as the charge polarity may change during heating.

The emergence of charges is facilitated by the fact that when the films are heated, some ions included in the film structure, as noted above, tend to change its oxidation state. In particular, a number of ions tend to be recovered by interaction with organic components (copper ions), while another to be oxidized by reactions with nitrates. Consequently, the charge polarity can be determined by the predominantly occurring redox processes and Red/Ox potentials. Moreover, there is a possibility of such a phenomenon as mechanic electron emission out of polymeric materials $[210,211]$ with decreased electron liberation, the tunneling phenomena are known to occur in these materials. When heated, the polymer saline films, as shown in $[150,196]$, undergo significant changes, sometimes alternating, in their geometry, which can lead in particular to mechanical stresses.

We give the charge polarities in some films as an example. In particular, positive charges are formed in the PVA ammonium heptamolybdate-containing compositions, the negative are formed in the copper nitrate compositions [210]. The negative charge was observed in nitrate-polymer precursors intended for synthesis of superconducting $\mathrm{YBa}_{2} \mathrm{Cu}_{3} \mathrm{O}_{7-\delta}$. When the formates of the respective metals were used as the salt constituents of this system, the initial positive charge was then changed to negative. In most cases, the most intensive process of film charge formation was temperature-correlated with maximum emission of gaseous compounds revealed during gravimetric analysis of the samples. The assessment showed that the measured film charges can emerge if a single elementary charge is generated upon removal of about 230,000 molecules out of the film to the gaseous environment. The charge-filling density of conditional traps per a space charge at specific film weight of $1.4 \mathrm{~g} / \mathrm{cm}^{3}$, according to the estimation, reaches the values of about $2 \cdot 10^{15}$ charges per cubic centimeter, i.e., approaches the limit values for certain polymeric film materials [211].

It is important that the newly formed charges are preserved on the oxide nanoparticles emerged after PSC pyrolysis at higher temperatures. Thus, during the synthesis of the samarium-doped cerium oxide, $\mathrm{Ce}_{1-x} \mathrm{Sm}_{x} \mathrm{O}_{2-d}$, there is a negative potential of about $400 \mathrm{~V}$ at the stage of solvent removal from the polymer-nitrate aqueous solutions by heating in a porcelain cup. After the composition combustion, the powder product produced had a negative charge and potential of about $200 \mathrm{~V}$ with respect to ground. The eponymous charges of the particles lead to their mutual repulsion. Depending on the magnitude of the particle charge, the combustion process forms the materials in which the aggregation is implemented to different extents, which greatly affects their ability to be sintered, in particular, the temperature interval of intensive powder sintering when producing ceramics. In the case of maximum charges, there are powders produced with minimal contact between the particles, large excess surface energy values, and accordingly, enhanced sintering behavior. In the case of lower charges, the excess surface energy is partly consumed during combustion, which leads to more close contacts, ensuring further existence of ensembles of particles which are more resistant to sintering. It helps control the properties of the resulting powders [212].

\section{Oxide material production by SCS}

The application of the above-described SCS method allows producing oxide nanomaterials both as nanopowders and nanocrystalline coatings on a variety of media, as well as controlling the properties of materials. Since the previous section addressed the occurrence of charges in precursors, we should comment on the ability to control the properties of materials using this phenomenon. There are ratios of organic components and nitrates which correspond to the most intensive SCS flow and the maximum thermal generation during the reaction (see, for example $[94,96,112,118,213])$. However, more significant charge accumulation was observed in compositions 
containing a substantial excess of the organic component. The combination of these factors leads to the fact that, in the first case, the synthesis leads to closely contacted ensembles of particles which are more resistant to sintering. In the second case, there are spot-contacted ensembles which are more prone to sintering at lower temperatures. This approach to control the powder properties is useful, for example, in producing solid-oxide fuel cells or electrochemical oxygen sources [214] when single-cycle sintering of the oxygen-conducting membrane with electrodes is economically and technically feasible. This requires, in particular, synchronizing the run of sintering temperature curves for different materials, for instance, for the strontium-doped lanthanum manganite and yttrium oxide-stabilized zirconium dioxide (YSZ). When using a similar material as a component of the applied catalytic systems, this, by contrast, requires providing greater resistance to sintering and preserving a specific surface area. It should be noted that the specific surface of the SCS-produced initial powders, however, differs slightly with different degree of particle contacts.

It should be noted that it is possible to generate oxides with variously sized crystallites by incrementally increasing the thermal treatment temperature of the SCS-produced powders [94-99, 130, 161]. As SCS oxide nanoparticles are prone to aggregation, their structure and dimensions should be studied by a complex of methods [215]. The studies in $[157,158,161,162,169,197,198,212,216]$ showed the necessity to use such methods as the x-ray diffraction, line broadening analysis, small-angle x-ray and neutron scattering, transmission electron microscopy, low-temperature gas adsorption curve analysis, etc.

One of the features of oxide material synthesis from organic-inorganic compositions is that the main or a substantial material portion formed in the combustion can be amorphous $[95,96,98,99,126,169,197,198]$. This, in particular, results in the possibility to significantly reduce the temperature of additional thermal treatment for final production. The transition from the amorphous to the crystalline superfine state can lead to formation of globular particles with a well-developed, including fractal, surface [130,159, 169, 197, 198]. Generally, the increased firing temperature leads to a smoothed surface of the particles [157-159, 161, 169, 197, 198]. At the time of crystallization, some of the material, as shown in [157-159,169,197,198] represents a combination of one- or two-dimensional formations, to which the concept of specific surface area is just conditionally applicable. Experimental measurements of the specific surface by sorption methods can give rather high values in these cases [157-161, 169,197,198]. Thus, the specific surface and fractal structure maxima can be incompatible, and the different structures of particles can be realized at the same value of the specific surface. For example, small globular particles with a smoother surface or greater ones, but with non-smooth boundary, can be formed. The latter may be preferable for use as catalysts, in particular with respect to the active center distribution and energetics. This should be considered when choosing conditions for the synthesis of catalysts and oxide materials of a different functional purpose.

The results of examining the possibilities and causes of impurity phases in oxide systems in the SCS processes bear interest in practical terms. We should note here that these impurity phases do not interfere with the successful use of materials in many cases $[126,130,158,160,165,169,201,212]$, although it is sometimes necessary to make the material be single-phase $[94,96,99,106,107,112,118,159,169]$. Heterogeneous solid-phase systems are used in catalysis where the impurity phases often play the role of promoters and co-catalysts, as in the silver-inclusive lanthanum manganites $[126,130,158,160]$. In the superconducting materials, a newly formed impurity can serve as a pinning center [169]. The possibilities of impurity emergence may be divided at least into two stages [169,217] in accordance with the steps of precursor production and combustion. In the first step, the formation of impurities (solutions) may be contributed by the relatively low solubility of specific salts, their formation of low-soluble compounds with other components, and hydrolysis of some compounds resulting in hydroxides. The latter applies, for example, to salts of transition metals, particularly iron, in cases where the acidity of solutions is insufficient. Against the background of organic-inorganic compositions, the newly formed hydroxides are sometimes difficult to see visually, however, their formation may be irreversible after aging of precipitations, which leads to broken homogeneity of the precursors.

At the stage of combustion, the formation of impurity phases is also possible due to the fact that different gas environment appears in SCS, depending on the precursor composition, as noted above. In terms of the reducing environment, some metal components are capable, as ions, of reducing up to the formation of impurity phases which include low-valent metals [130,150,151,165,169,202,217]. Such facts were recorded during the synthesis, although they were not always paid adequate attention. As an example, when producing ferrites, cobaltites, manganites with $\mathrm{ABO}_{3}$ (A stands for rare - earth and alkaline-earth elements, $\mathrm{B}$ stands for transition metal ions) perovskite structure, the impurity phases are often found [130,158,169,217], in particular, show that during the synthesis, the amount of the impurity phase depends on the component $\varphi$-ratio (PVA - nitrate). The distribution of impurities in the material produced can have a significant effect on its functional properties. In most cases, the optimal is the existence of nanoscale impurities as uniformly distributed in the main phase environment. By 
choosing the appropriate synthesis conditions in [130], it was managed to achieve, in particular, this distribution of silver nanoparticles in the doped lanthanum manganite.

There are interesting attempts to purposefully influence the texture of the resulting SCS oxide materials. Thus, in $[155,169]$, the synthesis was carried out in a magnetic field of the magnetic oxide phases with magnetoplumbitetype structure based on lanthanum and cobalt-doped strontium hexaferrite, $\mathrm{Sr}_{1-x} \mathrm{La}_{x} \mathrm{Fe}_{12-x} \mathrm{Co}_{x} \mathrm{O}_{19}$. As a result, they managed to increase the coercive material force, although they failed to significantly affect the magnitude of the residual specific magnetization. [155,169] showed the influence of the synthesis environment on coercive force of the magnets, which was increased during SCS in a reducing environment due to the generation of defects resulting from iron reduction to $\mathrm{Fe}^{2+}$.

In SCS production of oxide materials as catalytic coatings, they observed another variant of impurity phase formation which occurred due to interaction between the active nanosized catalyst particles and the intermediate carrier [212]. In particular, the formation of aluminum-manganese spinel of several nanometers thick, as found in [212], showed a marked promoter-wise effect in relation to the system which included aluminum oxide and perovskite. The effect was observed in oxidizing catalytic reactions of carbon monoxide and organic compounds, reduction of nitrogen oxides in a gaseous environment.

\section{Environmental aspects of the SCS implementation}

As shown in [112,118] and demonstrated in Fig. 21, an appreciable amount of carbon monoxide and nitrogen oxides may be released during SCS. To solve the problem of environmental protection, as it turned out, the nanostructured catalysts deposited on nickel foam with an aluminum oxide sublayer serve the purpose, as well as doped lanthanum manganites produced by SCS [130,158,160,202,212]. Even with a volley emission of nitrogen oxides and carbon monoxide during the pyrolysis of original compositions, the devices based on these catalysts can successfully cope with the purification of gases [130,157, 158, 160,202,212]. This is facilitated by both CO and NOx available in the waste gases, which are catalytically converted into $\mathrm{CO}_{2}$ and $\mathrm{N}_{2}$ in the hot pyrolytic gases.

Rapidly flowing SCS processes can be accompanied by significant emission of dust particles from the reaction zone. Taking into account the charges on the particles, the use of electrostatic precipitators is possible to trap the particles and their aggregates. Moreover, in some cases, additional ionization of the trapped particles is not required, and the process is implemented due to their own charge.

\section{Acknowledgments}

The authors thank sincerely their colleagues with whom they carried out this joint research, the results of which have been reflected in the review. A significant piece of work was performed with financial support within the State Assignment of the Ministry of Education and Science of the Russian Federation (Project No. 4.6653.2017/ BP) and the Ural Federal University Competitiveness Program (Project Code 14.594.21.0011).

\section{References}

[1] Knurova M.V., Mittova I.Ya., Perov N.S., Al'myasheva O.V., Tien N.A., Mittova V.O., Bessalova V.V., Viryutina E.L. Effect of the degree of doping on the size and magnetic properties of nanocrystals $\mathrm{La}_{1-x} \mathrm{Zn}_{x} \mathrm{FeO}_{3}$ synthesized by the sol-gel method. Russ. J. Inorg. Chem., 2017, 62(3), P. 281-287.

[2] Tien N.A., Mittova I.Ya., Solodukhin D.O., Al'myasheva O.V., Mittova V.O., Demidova S.Yu. Sol-gel formation and properties of nanocrystals of solid solutions $\mathrm{Y}_{1-x} \mathrm{Ca}_{x} \mathrm{FeO}_{3}$. Russ. J. Inorg. Chem., 2014, 59(2), P. 40-45.

[3] Tac D.V., Mittova V.O., Almjasheva O.V., Mittova I.Ya. Synthesis, structure, and magnetic properties of nanocrystalline $\mathrm{Y}_{3-x} \mathrm{La}_{x} \mathrm{Fe}_{5} \mathrm{O}_{12}(0 \leq \mathrm{x} \leq 0.6)$. Inorgan. Mater, 2012, 48(1), P. 74-78.

[4] Tac D.V., Mittova V.O., Almjasheva O.V., Mittova I.Ya. Synthesis and magnetic properties of nanocrystalline $\mathrm{Y}_{1-x} \mathrm{Cd}_{x} \mathrm{FeO}_{3-\delta}(0$ $\leq \mathrm{x} \leq$ 0.2). Inorgan. Mater., 2011, 47(10), P. 1141-1146.

[5] Tien N.A., Mittova I.Ya., Al'myasheva O.V. Influence of the synthesis conditions on the particle size and morphology of yttrium orthoferrite obtained from aqueous solutions. Russ. J. Appl. Chem., 2009, 82(11), P. 1915-1918.

[6] Chen L., He B.-Y., He S., Wang T.-J., Su C.-L., Jin Y. Fe-Ti oxide nano-adsorbent synthesized by co-precipitation for fluoride removal from drinking water and its adsorption mechanism. Powder Technology, 2012, 227, P. 3-8.

[7] Kolen'ko Y.V., Maksimov V.D., Garshev A.V., Mukhanov V.A., Oleynikov N.N., Churagulov B.R. Physicochemical properties of nanocrystalline zirconia hydrothermally synthesized from zirconyl chloride and zirconyl nitrate aqueous solutions. Russ. J. Inorg. Chem., 2004, 49(8), P. 1133-1137.

[8] Almamoun O., Ma S.Y. Effect of Mn doping on the structural, morphological and optical properties of $\mathrm{SnO}_{2}$ nanoparticles prepared by sol-gel method. Mater. Lett., 2017, 199, P. 172-175.

[9] Mahdavi R., Talesh S.S.A. The effect of ultrasonic irradiation on the structure, morphology and photocatalytic performance of ZnO nanoparticles by sol-gel method. Ultrasonics Sonochemistry, 2017, 39, P. 504-510.

[10] Vasilevskaya A.K., Almjasheva O.V., Gusarov V.V. Formation of nanocrystals in the $\mathrm{ZrO}_{2}-\mathrm{H}_{2} \mathrm{O}$ system. Russ. J. Gen. Chem., 2015, 85(12), P. 2673-2676. 
[11] Sharipov Kh.B., Yapryntsev A.D., Baranchikov A.E., Boytsova O.V., Kurzeev S.A., Ivanova O.S., Borilo L.P., Gil'mutdinov F.Z., Kozik V.V., Ivanov V.K. Synthesis of manganese dioxide by homogeneous hydrolysis in the presence of melamine. Russ. J. Inorg. Chem., 2017, 62(2), P. 139-149.

[12] Zhang M., An T., Liu X., Hu X., Fu J. Preparation of a high-activity $\mathrm{ZnO} / \mathrm{TiO}_{2}$ photocatalyst via homogeneous hydrolysis method with low temperature crystallization. Materials Letters, 2010, 64(17), P. 1883-1886.

[13] Sadrieyeh S., Malekfar R. The effects of hydrolysis level on structural properties of titania aerogels. J. Non-Crystall. Solids, 2017, 457, P. 175-179.

[14] Pechini M.P. Method of preparing lead and alkaline earth titanates and niobates and coating method using the same to form a capacitor. US 3330697 A. Filed Aug. 26, 1963, Ser. N 304, 437 Ckaims July 11, 1967.

[15] Abiev R.S., Almyasheva O.V., Gusarov V.V., Izotova S.G. Method of producing nanopowder of cobalt ferrite and microreactor to this end. Patent for invention N RU 2625981 C1. Date of publication: 20.07.2017 Bull. N 20. Effective date for property rights: 16.09.2016.

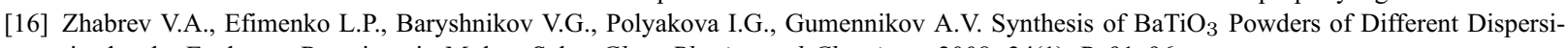
ties by the Exchange Reactions in Molten Salts. Glass Physics and Chemistry, 2008, 34(1), P. 91-96.

[17] Khokhlov V.A., Dokutovich V.N., Modenov D.V., Kochedykov V.A., Zakir'janova I.D., Korzun I.V., Nikolaeva E.V. Method of producing nanosize particles of complex metal oxides. RU 2461668 C1. Date of filing: 16.03.2011. Date of publication 20.09.2012. Bull. 26.

[18] Zhou H., Mao Y., Wong S.S. Probing Structure-Parameter Correlations in the Molten Salt Synthesis of BaZrO 3 Perovskite SubmicrometerSized Particles. Chem. Mater, 2007, 19, P. 5238-5249.

[19] Han P., Jiang X. Regulation on the synthesis temperature and optical properties of $\mathrm{SmBO}_{3}$ prepared by chloride fluxes assisted the solid state reaction method. Advanced Powder Technology, 2015, 26(3), P. 977-982.

[20] Morozov M.I., Lomanova N.A., Gusarov V.V. Specific features of $\mathrm{BiFeO}_{3}$ formation in a mixture of bismuth(III) and iron(III) oxides. Russ. J. Gen. Chem., 2003, 73(11), P. 1676-1680.

[21] Bingbing Liu, Yuanbo Zhang, Zijian Su, Manman Lu, Zhiwei Peng, Guanghui Li, Tao Jiang Formation mechanism of $\mathrm{Mn}_{x} \mathrm{Fe}_{3-x} \mathrm{O}_{4}$ by solid-state reaction of $\mathrm{MnO}_{2}$ and $\mathrm{Fe}_{2} \mathrm{O}_{3}$ in air atmosphere: Morphologies and properties evolution. Powder Technology, 2017, 313, P. 201-209.

[22] Morozov M.I., Mezentseva L.P., Gusarov V.V. Mechanism of formation of $\mathrm{Bi}_{4} \mathrm{Ti}_{3} \mathrm{O}_{12}$. Russ. J. Gen. Chem., 2002, 72(7), P. 1038-1040.

[23] Morozov M.I., Gusarov V.V. Synthesis of $\mathrm{A}_{m-1} \mathrm{Bi}_{2} \mathrm{M}_{m} \mathrm{O}_{3 m+3}$ compounds in the $\mathrm{Bi}_{4} \mathrm{Ti}_{3} \mathrm{O}_{12}-\mathrm{BiFeO}_{3}$ system. Inorganic Materials, 2002, 38(7), P. 723-729.

[24] Mikhailov M.M., Vlasov V.A., Utebekov T.A., Sokolovskiy A.N., Lovizkii A.A., Smolin A.E. Solid-state synthesis of LaSrMnO 3 powders for smart coatings. Mater. Research Bull., 2017, 89, P. 154-160.10.1016/j.materresbull.2017.01.038)

[25] Belkova T.B., Kostikov Yu.P., Neiman A.Ya. Solid-State Reactions of Bismuth Oxide with Transition- $\mathrm{Metal}_{\mathrm{O}} \mathrm{Oxides}\left(\mathrm{Cr}_{2} \mathrm{O}_{3}\right.$, $\mathrm{Mn}_{2} \mathrm{O}_{3}$, $\mathrm{Co}_{3} \mathrm{O}_{4}$ ). Russ. J. Inorg. Chem., 1999, 44(2), P. 161-166.

[26] Gusarov V.V., Suvorov S.A. Autocatalytic solid-phase reaction. J. Appl. Chem. USSR. 1987, 60(12), P. $1805-1808$.

[27] Gusarov V.V., Suvorov S.A. Autocatalytic solid-phase reaction of chrysoberyl formation. Zhurnal Obshchei Khimii, 1988, 58(4), P. 932934. (in Russian)

[28] Gusarov V.V. Fast Solid-Phase Chemical Reactions. Russ. J. Gen. Chem., 1997, 67(12), P. 1846-1851.

[29] Gusarov V.V., Ishutina Z.N., Malkov A.A., Malygin A.A. Peculiarities of the solid-phase chemical reaction in formation of mullite in the nanosize film composition. Doklady Akademii Nauk, 1997, 357(2), P. 203-205. (in Russian)

[30] Smirnova Z.N., Gusarov V.V., Malkov A.A., Firsanova T.V., Malygin A.A., Suvorov S.A. High-speed synthesis of mullite. Zhurnal Obshchei Khimii, 1995, 65(2), P. 199-204. (in Russian)

[31] Gusarov V.V., Malkov A.A., Malygin A.A., Suvorov S.A. Generation of aluminum titanate in compositions with high-level of space and structural conjugation of components. Zhurnal Obshchei Khimii, 1994, 64(4), P. 554-557. (in Russian)

[32] Gusarov V.V., Malkov A.A., Ishutina Z.N., Malygin A.A. Phase formation in a nanosize silicon oxide film on the surface of aluminum oxide. Technical Physics Letters, 1998, 24(1), P. 3-8.

[33] Fedorov N.F., Samonin V.V., Kruglikova I.V. Thermal decomposition of some hydroxides in metal melts. Russ. J. Appl. Chem., 1997, 70(2), P. 323-325.

[34] Kiselev E.A., Cherepanov V.A., Proskurnina N.V., Voronin V.I. Phase equilibria and crystal structures of phases in the La-Fe-Ni-O system at $1370 \mathrm{~K}$ in air. Inorgan. Mater, 2007, 43(2), P. 167-175.

[35] Bannikov D.O., Cherepanov V.A. Thermodynamical Stability of the Nickel-Lanthanum Complex Oxides. Z. Anorg. Allg. Chem., 2002, 628, P. 2180-2182.

[36] Kiselev E.A., Cherepanov V.A. $\mathrm{P}\left(\mathrm{O}_{2}\right)$-stability of $\mathrm{LaFe}_{1-x} \mathrm{Ni}_{x} \mathrm{O}_{3-\delta}$ solid solutions at $1100^{\circ} \mathrm{C}$. J. Solid State Chem., 2010, 183(9), P. 1992-1997.

[37] Lu J., Qiao L.J., Fu P.Z., Wu Y.C. Phase equilibrium of $\mathrm{Bi}_{2} \mathrm{O}_{3}-\mathrm{Fe}_{2} \mathrm{O}_{3}$ pseudo-binary system and growth of $\mathrm{BiFeO}$ single crystal. $J$. Cryst. Growth., 2011, 318, P. 936-941.

[38] Valant M., Axelsson A.-M., Alford N. Peculiarities of a solid-state synthesis of multiferroic polycrystalline BiFeO 3. Chem. Mater., 2007, 19, P. 5431-5436.

[39] Selbach S.M., Einarsrud M.-A., Grande T. On the thermodynamic stability of $\mathrm{BiFeO}_{3}$. Chem. Mater, 2009, 21, P. 169-173.

[40] Almjashev O.V., Gusarov V.V. Effect of $\mathrm{ZrO}_{2}$ nanocrystals on the stabilization of the amorphous state of alumina and silica in the $\mathrm{ZrO}_{2}-\mathrm{Al}_{2} \mathrm{O}_{3}$ and $\mathrm{ZrO}_{2}-\mathrm{SiO}_{2}$ systems. Glass Phys. Chem., 2006, 32(2), P. 162-166.

[41] Al'myashev O.V., Gusarov V.V. Features of the phase formation in the nanocomposites. Russ. J. Gen. Chem., 2010, 80(3), P. 385-390.

[42] Al'myasheva O.V., Gusarov V.V. Nucleation in media in which nanoparticles of another phase are distributed. Doklady Physical Chemistry, 2009, 424(2), P. 43-45.

[43] Boldyrev V.V. Mechanochemistry and mechanical activation of solids. Russ. Chem. Rev., 2006, 75(3), P. 177-189. 10.1070/RC2006v075n03ABEH001205)

[44] Kalinkin A.M., Balyakin K.V., Nevedomskii V.N., Kalinkina E.V. Solid-state synthesis of nanocrystalline strontium zirconate assisted by mechanical activation. Russ. J. Gen. Chem., 2016, 86(4), P. 785-791.

[45] Maurya D., Thota H., Nalwa K.S., Garg A. $\mathrm{BiFeO}_{3}$ ceramics synthesized by mechanical activation assisted versus conventional solidstate-reaction process: A comparative study. J. Alloys Compd., 2009, 477, P. 780-784. 
[46] Urakaev F.Kh. Mechanochemical synthesis of nanoparticles by a dilution method: optimization of the composition of a powder mixture. Mendeleev Communications. 2011, 21(5), P. 266-269.

[47] Liu W., Wang Q., Zhang J., Xie X., Xia B. Isothermal kinetic analysis of the effects of high-energy ball milling on solid-state reaction of $\mathrm{Li}_{4} \mathrm{Ti}_{5} \mathrm{O}_{12}$. Powder Technology, 2016, 287, P. 373-379.

[48] Clarke T.J., Davies T.E., Kondrat S.A., Taylor S.H. Mechanochemical synthesis of copper manganese oxide for the ambient temperature oxidation of carbon monoxide. Applied Catalysis B: Environmental, 2015, 165, P. 222-231.

[49] Maghsoudlou M.S.A., Ebadzadeh T., Sharafi Z., Arabi M., Zahabi K.R. Synthesis and sintering of nano-sized forsterite prepared by short mechanochemical activation process. J. Alloys Compd., 2016, 678, P. 290-296.

[50] Pavel O.D., Zăvoianu R., Bîrjega R., Angelescu E., Pârvulescu V.I. Mechanochemical versus co-precipitated synthesized lanthanum-doped layered materials for olefinoxidation. Applied Catalysis A: General, 2017, 542, P. 10-20.

[51] Livage J. Vanadium pentoxide gels. Chem. Mater., 1991, 3(4), P. 578.

[52] Kumar M., Srikantha S., Ravikumar B., Alex T.C, Das S.K. Synthesis of pure and Sr-doped $\mathrm{LaGaO}_{3}, \mathrm{LaFeO}_{3}$ and $\mathrm{LaCoO}_{3}$ and Sr, Mg-doped $\mathrm{LaGaO}_{3}$ for ITSOFC application using different wet chemical routes. Mater. Chem. Phys., 2009, 113, P. 803-815.

[53] Agafonov A.V., Afanas'ev D.A., Borilo L.P., Kraev A.S., Gerasimova T.V. Synthesis of nanostructured iron titanates by soft chemistry methods. Russ. J. Inorg. Chem., 2016, 61(5), P. 560-566.

[54] Li Y., Xu S. Hydrothermal synthesis of lanthanide (hydr)oxide micro/nanorods in presence of tetrabutylammonium hydroxide. J. Rare Earths, 2016, 34(6), P. 618-625.

[55] Bugrov A.N., Rodionov I.A., Zvereva I.A., Smyslov R.Yu., Almjasheva O.V. Photocatalytic activity and luminescent properties of Y, Eu, $\mathrm{Tb}$, Sm and Er-doped $\mathrm{ZrO}_{2}$ nanoparticles obtained by hydrothermal method. Int. J. Nanotechnology, 2016, 13(1/2/3), P. 147-157.

[56] Yu J., Tian N., Deng Y.F., Zhang H.H. Ultraviolet photodetector based on sol-gel synthesized MgZnO nanoparticle with photoconductive gain. J. Alloys Compd., 2016, 667, P. 359-362.

[57] Salavati-Niasari M., Soofivand F., Sobhani-Nasab A., Shakouri-Arani M., Bagheri S. Synthesis, characterization, and morphological control of $\mathrm{ZnTiO}_{3}$ nanoparticles through sol-gel processesand its photocatalyst application. Adv. Pow. Tech., 2016, 27(5), P. 2066-2075.

[58] Nguyen A.T., Phan Ph.H.Nh., Mittova I.Ya., Knurova M.V., Mittova V.O. The characterization of nanosized $\mathrm{ZnFe}_{2} \mathrm{O}_{4}$ material prepared by coprecipitation. Nanosystems: Physics, Chemistry, Mathematics, 2016, 7(3), P. 459-463.

[59] Tretyakov Yu.D., Shlyakhtin O.A. Recent progress in cryochemical synthesis of oxide materials. J. Mater. Chem., 1999, 9(1), P. 19-24.

[60] Tretyakov Yu.D., Oleynikov N.N., Shlyakhtin O.A. Cryochemical Technology of Advanced Materials. London: Chapman \& Hall, 1997. $319 \mathrm{p}$.

[61] Brylev O.A., Shlyakhtin O.A., Egorov A.V., Tretyakov Yu.D. Phase formation and electrochemical properties of cryochemically processed $\mathrm{Li}_{1+x} \mathrm{~V}_{3} \mathrm{O}_{8}$ materials. J. Power Sources, 2007, 164(2), P. 868-873.

[62] Byrappa K., Yoshimura M. Handbook of Hydrothermal Technology. Published in the United States of America by Noyes Publications. 2001. NY.

[63] Suchanek W.L., Riman R.E. Hydrothermal Synthesis of Advanced Ceramic Powders. Advances in Science and Technology, 2006, 45, P. 184-193.

[64] Pyda W., Haberko K., Bucko M.M. Hydrothermal crystallization of zirconia and zironia solid solutions. J. Am. Ceram. Soc., 1991, 74(10), P. 2622-2629.

[65] Somiya S., Akiba T. Hydrothermal zirconia powders: a bibliography. J. Europ. Ceram. Soc., 1999, 19 , P. $81-87$.

[66] Pozhidaeva O.V., Korytkova E.N., Drozdova I.A., Gusarov V.V. Phase state and particle size of ultradispersed zirconium dioxide as influenced by condition of hydrothermal synthesis. Russ. J. Gen. Chem., 1999, 69(8), P. 1219-1222.

[67] Meskin P.E., Baranchikov A.E., Ivanov V.K., Afanas'ev D.R., Gavrilov A.I., Churagulov B.R., Oleinikov N.N. Ultrasonically activated hydrothermal synthesis of fine $\mathrm{TiO}_{2}$ and $\mathrm{ZrO}_{2}$ powders. Inorg. Mater, 2004, 40(10), P. 1208-1215.

[68] Al'myasheva O.V., Korytkova E.N., Maslov A.V., Gusarov V.V. Preparation of nanocrystalline alumina under hydrothermal conditions. Inorg. Mater, 2005, 41(5), P. 540-547.

[69] Kimel R.A., Adair J.H. Aqueous synthesis at $200^{\circ} \mathrm{C}$ of sub-10 nanometer yttria tetragonally stabilized zirconia using a metal-ligand approach. J. Am. Ceram. Soc., 2005, 88(5), P. 1133-1138.

[70] Li J., Luo S., Ding X., Wang Q., He P. Hydrothermal synthesis of $\mathrm{LiAlO}_{2}$ nanostructures with high specific surface area by using anodized aluminum oxide template. Materials Letters, 2017, 196, P. 183-186.

[71] Meskin P.E., Ivanov V.K., Baranchicov A.E., Churagulov B.R., Tretyakov Yu.D. Ultrasonically assisted hydrothermal synthesis of nanocrystalline $\mathrm{ZrO}_{2}, \mathrm{TiO}_{2}, \mathrm{NiFe}_{2} \mathrm{O}_{4}$ and $\mathrm{Ni}_{0.5} \mathrm{Zn}_{0.5} \mathrm{Fe}_{2} \mathrm{O}_{4}$ powders. Ultrasonis Sonochemistry, 2006, 13, P. 47-53.

[72] Zhu H., Yang D., Xi Z., Zhu L. Hydrothermal synthesis and characterization of zirconia nanocristallites. J. Am. Ceram. Soc, 2007, 90(4), P. 1334-1338.

[73] Almjasheva O.V., Gusarov V.V. Hydrothermal synthesis of nanosized and amorphous alumina in the $\mathrm{ZrO}_{2}-\mathrm{Al}_{2} \mathrm{O}_{3}-\mathrm{H}_{2} \mathrm{O}$ system. Russ. J. Inorg. Chem., 2007, 52(8), P. 1194-1200.

[74] Korytkova E.N., Pivovarova L.N., Semenova O.E., Drozdova I.A., Povinich V.F., Gusarov V.V. Hydrothermal synthesis of nanotubular Mg-Fe hydrosilicate. Russ. J. Inorg. Chem., 2007, 52(3), P. 338-344.

[75] Kuklo L.I., Tolstoy V.P. Successive ionic layer deposition of $\mathrm{Fe}_{3} \mathrm{O}_{4} @ \mathrm{H}_{x} \mathrm{MoO}_{4} \cdot \mathrm{nH}_{2} \mathrm{O}$ composite nanolayers and their superparamagnetic properties. Nanosystems: Physics, Chemistry, Mathematics, 2016, 7(6), P. 1050-1054.

[76] Kuznetsova V.A., Almjasheva O.V., Gusarov V.V. Influence of microwave and ultrasonic treatment on the formation of $\mathrm{CoFe}_{2} \mathrm{O}_{4}$ under hydrothermal conditions. Glass Phys. Chem., 2009, 35(2), P. 205-209.

[77] Anikeev V.I. Hydrothermal synthesis of metal oxide nano- and microparticles in supercritical water. Russ. J. Phys. Chem., 2011, 85(3), P. 377-382.

[78] Gavrilov A.I., Kapitanova O.O., Baranov A.N., Churagulov B.R. Specifics of hydrothermal synthesis of oriented zinc oxide nanorods on metallic zinc substrates. Russ. J. Inorg. Chem., 2012, 57(9), P. 1182-1186.

[79] Phuruangrat A., Thongtem S., Thongtem T. Microwave-assisted hydrothermal synthesis and characterization of $\mathrm{CeO}_{2}$ nanowires for using as a photocatalytic material. Materials Letters, 2017, 196, P. 61-63.

[80] Cheng W., Xu X., Wu F., Li J. Synthesis of cavity-containing iron oxide nanoparticles by hydrothermal treatment of colloidal dispersion. Materials Letters, 2016, 164, P. 210-212. 
[81] Popkov V.I., Almjasheva O.V. Formation mechanism of $\mathrm{YFeO}_{3}$ nanoparticles under the hydrothermal condition. Nanosystems: Physics, Chemistry, Mathematics, 2014, 5(5), P. 703-708.

[82] Bugrov A.N., Almjasheva O.V. Effect of hydrothermal synthesis conditions on the morphology of $\mathrm{ZrO}_{2}$ nanoparticles. Nanosystems: Physics, Chemistry, Mathematics, 2013, 4(6), P. 810-815.

[83] Almjasheva O.V. Formation and structural transformations of nanoparticles in the $\mathrm{TiO}_{2}-\mathrm{H}_{2} \mathrm{O}$ system. Nanosystems: Physics, Chemistry, Mathematics, 2016, 7(6), P. 1031-1049.

[84] Almjasheva O.V., Garabadzhiu A.V., Kozina Yu.V., Litvinchuk L.F., Dobritsa V.P. Biological effect of zirconium dioxide-based nanoparticles. Nanosystems: Physics, Chemistry, Mathematics, 2017, 8(3), P. 391-396.

[85] Simonenko N.P., Nikolaev V.A., Simonenko E.P., Generalova N.B., Sevastyanov V.G., Kuznetsov N.T. Preparation of nanostructured titania thin films by sol-gel technology. Russ. J. Inorg. Chem., 2016, 61(12), P. 1505-1511.

[86] Chick L.A., Pederson L.R., Maupin G.D., Bates J.L., Thomas L.E., Exarhos G.J. Glycine-nitrate combustion synthesis of oxide ceramic powders. Mater. Lett., 1990, 10(1-2), P. 6-12.

[87] Aruna S.T. Solution combustion synthesis. Concise Encyclopedia of Self-Propagating High-Temperature Synthesis, 2017, P. 344-346.

[88] Merzhanov A.G., Borovinskaya I.P. Self-Propagating High-Temperature Synthesis of Refractory Inorganic Compounds. Dokl. Akad. Nauk SSSR, 1972, 204, P. 429-432.

[89] Rogachev A.S., Varma A., Merzhanov A.G. The mechanism of self-propagating high-temperature synthesis of nickel aluminides. Pt. 1. Formation of the product microstructure in a combustion wave. Int. J. SHS, 1993, 2(1), P. 25-38.

[90] Merzhanov A.G. SHS Process: Combustion Theory and Practice. Archivum Combustionis, 1981, 1, P. $23-48$.

[91] Merzhanov A.G. Theory and Practice of SHS: Worldwide State of the Art and the Newest Results. Int. J. SHS, 1993, 2(2), P. 113-158.

[92] Tret'yakov Yu.D. Self-organisation processes in the chemistry of materials. Russ. Chem. Reviews, 2003, 72(8), P. 651-679.

[93] Tugova E., Yastrebov S., Karpov O., Smith R. $\mathrm{NdFeO}_{3}$ nanocrystals under glycine nitrate combustion formation. J. Crystal Growth, 2017, 467, P. 88-92.

[94] Popkov V.I., Almjasheva O.V. Yttrium orthoferrite $\mathrm{YFeO}_{3}$ nanopowders formation under glycine-nitrate combustion conditions. Russ. J. Appl. Chem., 2014, 87(2), P. 167-171.

[95] Popkov V.I., Almjasheva O.V., Gusarov V.V. The investigation of the structure control possibility of nanocrystalline yttrium orthoferrite in its synthesis from amorphous powders. Russ. J. Appl. Chem., 2014, 87(10), P. 1417-1421.

[96] Popkov V.I., Almjasheva O.V., Nevedomskiy V.N., V.V. Sokolov V.V., Gusarov V.V. Crystallization behaviour and morphological features of $\mathrm{YFeO}_{3}$ nanocrystallites obtained by glycine-nitrate combustion. Nanosystems: Physics, Chemistry, Mathematics, 2015, 6(6), P. 866874.

[97] Popkov V.I., Almjasheva O.V., Schmidt M.P., Izotova S.G., Gusarov V.V. Features of nanosized $\mathrm{YFeO}_{3}$ formation under heat treatment of glycine-nitrate combustion products. Russ. J. Inorg. Chem., 2015, 60(10), P. 1193-1198.

[98] Popkov V.I., Almjasheva O.V., Panchuk V.V., Semenov V.G., Gusarov V.V. The Role of pre-nucleus states in formation of nanocrystalline yttrium orthoferrite. Doklady Chemistry, 2016, 471(2), P. 356-359.

[99] Lomanova N.A., Tomkovich M.V., Sokolov V.V., Gusarov V.V. Special Features of Formation of Nanocrystalline BiFeO 3 via the Glycine-Nitrate Combustion Method. Russ. J. Gen. Chem., 2016, 86(10), P. 2256-2262.

[100] Shravana Kumara K.N., Nagaswarupa H.P., Vishnu Mahesh K.R., Prashantha S.C., Mylarappa M., Siddeshwara D.M.K. Synthesis and characterization of nano $\mathrm{ZnO}$ and $\mathrm{MgO}$ powder by low temperature solution combustion method: studies concerning electrochemical and photocatalytic behavior. Nanosystems: Physics, Chemistry, Mathematics, 2016, 7(4), P. 662-666.

[101] Rubalajyothi P., Nehru L.C. Photoluminescence characteristics of nanocrystalline $\mathrm{Ba}_{0.97} \mathrm{Ca}_{0.03} \mathrm{SO}_{4}$ :Eu by combustion method. Nanosystems: Physics, Chemistry, Mathematics, 2016, 7(3), P. 561-564.

[102] Chen Y., Yang J., Wang X., Feng F., Zhang Y., Tang Y. Synthesis $\mathrm{YFeO}_{3}$ by salt-assisted solution combustion method and its photocatalytic activity. J. Ceram. Soc. Japan., 2014, 122(2), P. 146-150.

[103] Wu L., Yu J.C., Zhang L., Wang X., Li S. Selective self-propagating combustion synthesis of hexagonal and orthorhombic nanocrystalline yttrium iron oxide. J. Solid State Chem., 2004, 177(10), P. 3666-3674.

[104] Komlev A.A., Vilezhaninov E.F. Glycine-nitrate combustion synthesis of nanopowders based on nonstoichiometric magnesium-aluminum spinel. Russ. J. Appl. Chem., 2013, 86(9), P. 1373-1380.

[105] Komlev A.A., Gusarov V.V. Glycine-nitrate combustion synthesis of nonstoichiometric Mg-Fe spinel nanopowders. Inorg. Mater., 2014, 50(12), P. 1247-1251.

[106] Zaboeva E.A., Izotova S.G., Popkov V.I. Glycine-nitrate combustion synthesis of $\mathrm{CeFeO}_{3}$-based nanocrystalline powders. Russ. J. Appl. Chem., 2016, 89(8), P. 1228-1236.

[107] Layek S., Verma H.C. Magnetic and dielectric properties of multiferroic $\mathrm{BiFeO}_{3}$ nanoparticles synthesized by a novel citrate combustion method. Adv. Mat. Lett. 2012, 3(6), P. 533-538.

[108] Zhuravlev V.D., Bamburov V.G., Beketov A.R., Perelyaeva L.A., Baklanova I.V., Sivtsova O.V., Vasil'ev V.G., Vladimirova E.V., Shevchenko V.G., Grigorov I.G. Solution combustion synthesis of $\alpha-\mathrm{Al}_{2} \mathrm{O}_{3}$ using urea. Ceram. Int., 2013, 39(2), P. 1379-1384.

[109] Popkov V.I., Almjasheva O.V., Semenova A.S., Kellerman D.G., Nevedomskiy V.N., Gusarov V.V. Magnetic properties of YFeO 3 nanocrystals obtained by different soft-chemical methods. J. Mater. Sci.: Materials in Electronics, 2017, 28(10), P. 7163-7170.

[110] Yang J., Li X., Zhou J., Tang Y., Zhang Y., Li Y. Factors controlling pure-phase magnetic BiFeO 3 powders synthesized by solution combustion synthesis. J. Alloys Compd., 2011, 509, P. 9271-9277.

[111] Farhadi S., Zaidi M. Bismuth ferrite $\left(\mathrm{BiFeO}_{3}\right)$ nanopowder prepared by sucrose-assisted combustion method: A novel and reusable heterogeneous catalyst fore acetylation of amines, alcohols and phenols under solvent-free conditions. J. Molecular Catalysis A: Chemical, 2009, 299, P. 18-25.

[112] Khaliullin Sh.M., Zhuravlev V.D., Russkikh O.V., Ostroushko A.A., Bamburov V.G. Thermal characteristics, gassing in solution combustion synthesis and conductivity of $\mathrm{CaZrO}_{3}$. Internat. J. Self-Propag. High-Temp. Synt., 2015, 24(2), P. 83-88.

[113] Ye T., Guiwen Z., Weiping Z., Shangda X. Combustion synthesis and photoluminescence of nanocrystalline $\mathrm{Y}_{2} \mathrm{O}_{3}:$ Eu phosphors. Mater. Res. Bull., 1997, 32(5), P. 501-506.

[114] Nagaveni K., Hegde M.S., Madras G. Structure and Photocatalytic Activity of $\mathrm{Ti}_{1-x} \mathrm{M}_{x} \mathrm{O}_{2 \pm \delta}(\mathrm{M}=\mathrm{W}, \mathrm{V}, \mathrm{Ce}, \mathrm{Zr}$, Fe, and Cu) Synthesized by Solution Combustion Method. J. Phys. Chem. B., 2004, 108(52), P. 20204-20212. 
[115] Mokkelbost T., Kaus I., Grande T., Einarsrud M.-A. Combustion Synthesis and Characterization of Nanocrystalline CeO 2 -Based Powders. Chem. Mater, 2004, 16(25), P. 5489-5494.

[116] Jose R., James J., John A.M., Sundararaman D., Divakar R., Koshy J. A new combustion process for nanosized YBa 2 ZrO 5.5 powders. Nanostructured Mater, 1999, 11(5), P. 623-629.

[117] Chiu T.-W., Yu B.-S., Wang Y.-R., Chen K.-T., Lin Y.-T. Synthesis of nanosized $\mathrm{CuCrO}_{2}$ porous powders via a self-combustion glycine nitrate process. J. Alloys Compd., 2011, 509(6), P. 2933-2935.

[118] Khaliullin Sh.M., Bamburov V.G., Russkikh O.V., Ostroushko A.A., Zhuravlev V.D. CaZrO 3 synthesis in combustion reactions with glycine. Dokl Chem., 2015, 461(2), P. 93-95.

[119] Bansal N.P., Zhong Z. Combustion synthesis of $\mathrm{Sm}_{0.5} \mathrm{Sr}_{0.5} \mathrm{CoO}_{3-x}$ and $\mathrm{La}_{0.6} \mathrm{Sr}_{0.4} \mathrm{CoO} 3-x$ nanopowders for solid oxide fuel cell cathodes. J. Power Sources, 2006, 158(1), P. 148-153.

[120] Yang X., Cheng X., Yan X., Yang J., Fu T., Qiu J. Synthesis of $\mathrm{ZrO}_{2} / \mathrm{ZrW}_{2} \mathrm{O}_{8}$ composites with low thermal expansion. Compos. Sci. Technol., 2007, 67(6), P. 1167-1171.

[121] Smirnova M.N., Nikiforova G.E., Kop'eva M.A., Beresnev E.N., Kondrat'eva O.N., Ketsko V.A., Geras'kin A.A. Features of $\mathrm{Mg}\left(\mathrm{Fe}_{0.8} \mathrm{Ga}_{0.2}\right)_{2} \mathrm{O}_{4}$ synthesis by glycine-nitrate method. Russ. J. Inorg. Chem., 2015, 60(8), P. 930-933.

[122] Ketsko V.A., Beresnev E.N., Komova M.G., Kop'eva M.A., Geras'kin A.A., Kuznetsov N.T. $\mathrm{MgAl}_{0.4} \mathrm{Fe}_{1.6} \mathrm{O}_{4}$ powders prepared via gel combustion. Russ. J. Inorg. Chem., 2012, 57(6), P. 794-796.

[123] Smirnova M.N., Goeva L.V., Simonenko N.P., Beresnev E.N., Kop'eva M.A., Ketsko V.A. Gel formation specifics in the synthesis of $\mathrm{Mg}\left(\mathrm{Fe}_{0.8} \mathrm{Ga}_{0.2}\right)_{2} \mathrm{O}_{4}$ by the glycine-nitrate method. Russ. J. Inorg. Chem., 2016, 61(10), P. 1301-1306.

[124] Beresnev E.N., Smirnova M.N., Simonenko N.P., Makaev S.V., Kop'eva M.A., Ketsko V.A., Kuznetsova O.B. Gel decomposition and formation of $\mathrm{MgFe}_{1.6} \mathrm{Ga}_{0.4} \mathrm{O}_{4}$ powders. Russ. J. Inorg. Chem., 2016, 61(8), P. 1026-1030.

[125] Chen X., Liang S.-J., Bi J.-H., Gao J., Wu L. Self-propagating Combustion Synthesis of Nanocrystalline Yttrium Iron Oxide Solid Solution Photocatalysts. Chinese J. Inorg.Chem., 2009, 25(11), P. 1922-1927.

[126] Ostroushko A.A., Russkikh O.V., Chezganov D.S. Formation and morphology of nickel foam-complex oxide coatings with the perovskite structure. J. of Surf. Invest. X-ray, Synch. and Neut. Tech, 2015, 9(6), P. 1237-1242.

[127] Ostroushko A.A., Mogil'nikov Yu.V., Ostroushko I.P. Synthesis of Molybdenum- and vanadium-Containing Mixed Oxides in Polymer-Salt Systems. Inorg. Mat., 2000, 36(12), P. 1256-1263.

[128] Ingle J.T., Sonekar R.P., Omanwar S.K., Wang Y., Zhao L. Solution combustion synthesis and optimization of phosphors for plasma display panels. Optical Materials, 2014, 36(8), P. 1299-1304.

[129] Abasht B., Mirkazemi S. M., Beitollahi A. Solution combustion synthesis of Ca hexaferrite using glycine fuel. J. Alloys Compd., 2017, 708, P. 337-343.

[130] Russkikh O.V., Ivanov D.V., Isupova L.A., Chezganov D.S., Ostroushko A.A. Synthesis, Morphology, and Activity of $\mathrm{La}_{1-x} \mathrm{Ag}_{x} \mathrm{MnO}_{3 \pm y}$ Catalysts. Kin. and Cat., 2016, 57(5), P. 712-721.

[131] Wang X., Qin M., Fang F., Jia B., Wu H., Qu X., Volinsky A.A. Effect of glycine on one-step solution combustion synthesis of magnetite nanoparticles. J. Alloys Compd., 2017, 719, P. 288-295.

[132] Novikov V., Xanthopoulou G., Knysh Yu., Amosov A.P. Solution combustion synthesis of nanoscale Cu-Cr-O spinels: Mechanism, properties and catalytic activity in CO oxidation. Ceramics International, 2017.

[133] Vojisavljevizh K., Wicker S., Can I., Benan A., Barsan N., Malia B. Nanocrystalline cobalt-oxide powders by solution-combustion synthesis and their application in chemical sensors. Advanced Powder Technology, 2017, 28(4), P. 1118-1128.

[134] Petschnig L.L., Fuhrmann G., Schildhammer D., Tribus M., Schottenberger H., Huppertz H. Solution combustion synthesis of CeFeO 3 under ambient atmosphere. Ceramics International, 2016, 42(3), P. 4262-4267.

[135] Nabiyouni M., Zhou H., Luchini T.J.F., Bhaduri S.B. Formation of nanostructured fluorapatite via microwave assisted solution combustion synthesis. Materials Science and Engineering: C, 2014, 37, P. 363-368.

[136] Tarragó D.P., de Fraga Malfatti C., de Sousa V.C. Influence of fuel on morphology of LSM powders obtained by solution combustion synthesis. Powder Technology, 2015, 269, P. 481-487.

[137] Varma A., Mukasyan A.S., Deshpande K.T., Pranda P., Erri P.R. Combustion Synthesis of Nanoscale Oxide Powders: Mechanism, Characterization and Properties. MRS Proc., 2003, 800, P. AA4.1-AA4.12.

[138] Mukasyan A.S., Epstein P., Dinka P. Solution combustion synthesis of nanomaterials. Proc. Combust. Inst., 2007, 31(2), P. 1789-1795.

[139] Aruna S.T., Mukasyan A.S. Combustion synthesis and nanomaterials. Curr. Opin. Solid State Mater. Sci., 2008, 12(3-4), P. 44-50.

[140] Patil K.C., Hegde M.S., Rattan T., Aruna S.T. Chemistry of Nanocrystalline Oxide Materials - Combustion Synthesis, Properties and Applications. Singapore: World Scientific Publishing Co. Pte. Ltd., 2008, 364 pp.

[141] Chen X., Liang S.-J., Bi J.-H., Gao J., Wu L. Self-propagating Combustion Synthesis of Nanocrystalline Yttrium Iron Oxide Solid Solution Photocatalysts. Chinese J. Inorg.Chem., 2009, 25(11), P. 1922-1927.

[142] Rogachev A.S., Mukasyan A.S. Combustion of heterogeneous nanostructural systems. Combust. Explos. Shock Waves, 2010, 46(3), P. 243-266.

[143] Sutka A., Mezinskis G. Sol-gel auto-combustion synthesis of spinel-type ferrite nanomaterials. Front. Mater. Sci., 2012 , 6(2), P. 128-141.

[144] Gonzalez-Cortes S.L., Imbert F.E. Fundamentals, properties and applications of solid catalysts prepared by solution combustion synthesis (SCS). Appl. Catal. A Gen., 2013, 452, P. 117-131.

[145] Rogachev A.S., Mukasyan A.S. Combustion for Material Synthesis. Boca Raton: CRC Press. 2014.424 pp.

[146] Li F.-T., Ran J., Jaroniec M., Qiao S.Z. Solution combustion synthesis of metal oxide nanomaterials for energy storage and conversion. Nanoscale, 2015, 7(42), P. 17590-17610.

[147] Varma A., Mukasyan A.S., Rogachev A.S., Manukyan K.V. Solution Combustion Synthesis of Nanoscale Materials. Chem. Rev., 2016, 116(23), P. 14493-14586.

[148] Khaliullin S.M., Zhuravlev V.D., Bamburov V.G. Solution-combustion synthesis of oxide nanoparticles from nitrate solutions containing glycine and urea: Thermodynamic aspects. Int. J. SHS., 2016, 25(3), P. 139-148.

[149] Ostroushko A.A., Shuravljova L.I., Portnova S.M., Krasilov Yu.I. Formation of grains in $\mathrm{YBa}_{2} \mathrm{Cu}_{3} \mathrm{O}_{7-\delta}$ powders. Zhurn. Neorg. Khim., 1991, 36(1), P. 3-5. (in Russian) 
[150] Ostroushko A.A., Portnova S.M., Krasilov Yu.I., Ostroushko I.P. The processes involved in the synthesis of oxide compounds from polymer-containing salt solutions. Zhurn. Neorg. Khim., 1991, 36(4), P. 465-468.

[151] Ostroushko A.A., Shuravljova L.I., Portnova S.M., Krasilov Yu.I. The use of formats to obtain HTSC films. Zhurn. Neorg. Khim., 1991, 36(5), P. 623-625.

[152] Ostroushko A.A., Shuravljova L.I. Osipov V.V. Some special properties of $\mathrm{La}_{1-\mathrm{x}} \mathrm{Sr}_{\mathrm{X}} \mathrm{CoO}_{3 \pm \mathrm{y}}$ films fabricated with the spray-pyrolysis method. Mat. Sci. and Eng., 1992, 149(2), P. L.17-L.19.

[153] Ostroushko A.A., Mironova N.V., Ostroushko I.P., Petrov A.N. Crystallization of saline components in polymer films during $\mathrm{YBa}_{2} \mathrm{Cu}_{3} \mathrm{O}_{7-\delta}$ synthesis. Zhurn. Neorg. Khim., 1992, 37(12), P. 2627-2631. (in Russian)

[154] Ostroushko A.A., Kwasnitza K., Widmer Ch, Aksionova V.I., Petrov A.N. Interaction of $\mathrm{YBa}_{2} \mathrm{Cu}_{3} \mathrm{O}_{7-\delta}$ Coating with Metallic Substrates. Zhurn. Neorg. Khim., 1993, 38(3), P. 436-438. (in Russian)

[155] Udilov A.E., Ostroushko A.A., Kudrevatyh N.V., Andreev S.V., Veselkina V.N. Preparing of the fine powdered $\operatorname{Sr}_{1-x} \operatorname{La}_{x} \mathrm{Fe}_{12-x} \mathrm{Co}_{x} \mathrm{O}_{19}$ $(\mathrm{x}=0 ; 0.2)$ by pyrolysis of polymeric-salt compositions. Abstracts of XIV International Conference on Permanent Magnets, Suzdal, 22-26 September 2003, P. 97.

[156] Ostroushko A.A., Shuravjova L.I., Kononchuk O.F., Petrov A.N. Fabrication of films $\mathrm{La}_{1-x} \mathrm{SrCoO}_{3}$ from salt solutions through pyrolysis method. Zhurn. Neorg. Khim., 1991, 36(1), P. 6-8. (in Russian)

[157] Ostroushko A.A., Zhuravleva L.I., Mogil'nikov Yu.V., Pirogov A.N. Catalytic Activity of Mixed-oxide Coating Based on Perovskite Lanthanum Strontium Cobaltate. Russ. J. of Inorg. Chem., 1997, 42(6), P. 836-840.

[158] Ostroushko A.A., Shubert E., Zhuravleva L.I., Isupova L.A., Alikina G.M., Bogdanov S.G., Valiev E.Z., Pirogov A.N., Teplykh A.E., Mogil'nikov Yu.V., Udilov A.E., Ostroushko I.P. Synthesis and Physicochemical and catalytic Properties of Perovskites $\mathrm{ABO}_{3 \pm y}(\mathrm{~A}=$ La, Sr, Ag; B = Mn, Co, Fe, Cu, Ti, Mo, V). Russ. J. Appl. Chem., 2000, 73(8), P. 1383-1392.

[159] Bogdanov S.G., Valiev E.Z., Pirogov A.N., Teplykh A.E., Ostroushko A.A, Udilov A.E. Magnetic and Fractal Properties of Nanocrystalline $\mathrm{LaMnO}_{3}$. The Phys. of Met. and Metallog., 2001, 91(1), P. S229-S233.

[160] Ostroushko A.A, Schubert E., Makarov A.M., Minaev V.I., Udilov A.E., Elokhina L.V., Aksionova V.I. Catalytic Activity of ComplexOxide Perovskit Containing Compositions in Reactions of CO and Organic Compounds Oxidation. Russ. J. Appl. Chem., 2003, 76(8), P. 1292-1297.

[161] Teplykh A.E., Bogdanov S.G., Valiev E.Z., Pirogov A.N., Dorofeev Yu.A., Kazantsev V.A., Kar'kin A.E., Ostroushko A.A., Udilov A.E. Size Effect in Nanocrystalline Manganites $\mathrm{La}_{1-x} \mathrm{~A}_{x} \mathrm{MnO}_{3}(\mathrm{~A}=\mathrm{Ag}$, Sr). Phys. Solid State, 2003, 45(12), P. 2328-2333.

[162] Ostroushko A.A., Russkikh O.V., Prosvetova M.V., Petrova S.A., Zakharov R.G. Phase Composition and Thermal Properties of $\mathrm{Ce}_{1-x} \operatorname{Ln}_{x} \mathrm{O}_{2-d}(\mathrm{Ln}=\mathrm{Sm}, \mathrm{Pr})$ Solid Solutions. Inorg. Mat., 2010, 46(9), P. 959-964.

[163] Ostroushko A., Kwasnitza K., Widmer Ch. Crysallization of $\mathrm{YBa}_{2} \mathrm{Cu}_{3} \mathrm{O}_{7-\delta}$ on films with single crystal and powder-metallic substrats made from salt-polymer solutions. Final book of abstracts. Intern. Conf. on Advanced Materials (ICAM-91). Strasbourg. France. 1991. A1-XII/P.58.

[164] Ostroushko A.A., Russkih O.V., Pivchenko S.V. Study of properties of catalysts for the oxidation of carbon black prepared by "ceramic" synthesis and by pyrolysis of polymeric salt compositions. Russ. J. Appl. Chem., 2010, 83(6), P. 1102-1105.

[165] Ostroushko A.A. Polymer-salt composites based on nonionic water-soluble polymers and preparation of oxide materials from them. Mendeleev Chem. J., 1998, 42(1-2), P. 153-168.

[166] Gusarov V.V., Suvorov S.A. Transformations of nonautonomous phases and densification of polycrystalline systems. J. Appl. Chem. USSR, 1992, 65(7), P. 1227-1235.

[167] Gusarov V.V., Malkov A.A., Malygin A.A., Suvorov S.A. Thermally activated transformations of 2D nonautonomous phases and contraction of polycrystalline oxyde materials. Inorg. Mater., 1995, 31(3), P. 320-323.

[168] Mazurin O.V., Gusarov V.V. The future of information technologies in materials science. Glass Phys. Chem., 2002, 28(2), P. 50-58.

[169] Anziferov V.N., Ostroushko A.A., Makarov A.M. Synthesis, properties and applications of catalysts based on modified complex oxide compositions of highly porous cellular materials. (Sintez, svoistva i primenenie katalizatorov na osnove modifizirovannikh slognooksinimi komposiziyami visokoporistykh yacheistikh materialov). Perm: Izd-vo Perm. gos. teh. un-ta, 2008, 204 pp. (in Russian).

[170] Ostroushko A.A., Vilkova N.V. Phase relations in ammonium heptamolybdate-poly(vinyl alcohol)-water mixtures. Russ. J. Inorg. Chem., 2001, 46(8), P. 1240-1243.

[171] Ostroushko A.A., Reshetnikova N.V. Phase relations and physicochemical properties of the ammonium vanadate - poly(vinyl alcohol) water system. Russ. J. Inorg. Chem., 2002, 47(11), P. 1745-1749.

[172] Ostroushko A.A., Minyaev V.I. Phase relations in the lanthanum nitrate - poly(vinyl alcohol) - water system. Russ. J. Inorg. Chem., 2003, 48(11), P. 1728-1730.

[173] Ostroushko A.A., Sennikov M.Y. Ammonium heptamolybdate - poly(vinylpyrrolidone) - water system. Russ. J. Inorg. Chem., 2003, 48(4), P. 572-577.

[174] Ostroushko A.A., Mikhalev D.S. Phase relations and physicochemical properties of the ammonium paratungstate - polyvinyl alcohol water system. Russ. J. Inorg. Chem., 2003, 48(3), P. 431-434.

[175] Ostroushko A.A., Sennikov M.Y., Glazyrina Y.A. Phase transitions in the ammonium heptamolybdate - poly(vinyl alcohol) - water system. Russ. J. Inorg. Chem., 2005, 50(2), P. 280-285.

[176] Ostroushko A.A., Sennikov M.Yu., Glazyrina Yu.A. Phase state and physicochemical properties of systems containing ammonium tungstate or ammonium vanadate, polyvinylpyrrolidone, and water. Russ. J. Inorg. Chem., 2007, 52(2), P. 254-257.

[177] Ostroushko A.A., Sennikov M.Yu. Phase relations in the lanthanum nitrate (copper nitrate) - poly(vinylpyrrolidone) - water systems. Russ. J. Inorg. Chem., 2007, 52(10), P. 1634-1637.

[178] Ostroushko A.A., Slinkina M.V., Volosentseva L.I., Ostroushko I.P, Mironova N.V., Pimenov D.A. Study of cation migration in polymer saline compositions based on polyvinyl-alcohol. Zhurn. Fizich. Khim., 1993, 67(11), P. 2267-2270. (in Russian)

[179] Ostroushko A.A., Zubarev A.Yu., Grzhegorzhevskii K.V. Evolution of Ammonium Metavanadate Crystals in Polyvinyl Alcohol Films. Cryst. Reports, 2016, 61(2), P. 320-326.

[180] Safronov A.P., Zyryanova A.N., Gabdrafikova Y.M., Ostroushko A.A. Enthalpy of interaction in poly(vinyl alcohol) - ammonium heptamolybdate composition: Effect of complex formation and structural changes. Polym. Scien. Ser. A., 2003, 45(10), P. 1052-1058. 
[181] Safronov A.P., Gabdrafikova Y.M., Ukhalina O.L., Ostroushko A.A. Enthalpy of formation of poly(vinyl alcohol), poly(ethylene glycol), and polyvinylpyrrolidone complexes with copper and cadmium ions in aqueous solutions. Polym. Scien. Ser. A., 2004, 46(5), P. $541-547$.

[182] Ostroushko A.A., Zubarev A.Y., Bublik I.V., Sennikov M.Y., Iskakova L.Y., Safronov A.P. Modeling and calculation of the association processes between oxygen-containing polyanions and nonionic polymers. Russ. J. Inorg. Chem., 2004, 49(7), P. 1028-1033.

[183] Lileev A.S., Lyashchenko A.K., Ostroushko A.A., and Sennikov M.Yu. Dielectric Properties of Aqueous Solutions of the Ammonium Heptamolybdate - Poly(vinyl Alcohol) - Water System. Russ. J. Inorg. Chem., 2006, 51(4), P. 656-661.

[184] Ostroushko A.A., Adamova L.V., Eremina E.V. Thermodynamic Characteristics of the Interaction between Methanol and Keplerate-Type Poly(vinyl alcohol) - Polyoxomolybdate Composites. Russ. J. Phys. Chem. A, 2017, 91(8), P. 1535-1538. (DOI: $10.1134 / \mathrm{S} 0036024417080258)$

[185] Kuznetsova A.E., Gradova N.B. Scientific basis of environmental biotechnology. Moscow, Mir, 2006, 504 pp. (in Russian)

[186] Pomogailo A.D. Polymeric immobilized metal-complex catalysts. Moscow, Nauka, 1988, 303 pp. (in Russian)

[187] Ostroushko A.A., Vilkova N.V., Mogil'nikov U.V. Structure and properties of molybdate and tungstate complexes of polyvinyl alcohol. Russ. J. Gen. Chem., 2002, 72(1), P. 1-8.

[188] Zubarev A.Yu., Ostroushko A.A., Bublik I.V., Sennikov M.Yu. Simulation of the rheological properties of liquid media containing solid anisometric particles. Coll. J., 2007, 69(6), P. 726-734.10.1134/S1061933X07060087)

[189] Ostroushko A.A., Mogil'nikov Y.V., Popov K.A. Polymer-salt compositions containing anionic d-metal species. Zhurn. Neorg. Khim., 1998, 43(6), P. 840-845.

[190] Men'shikov S.Yu., Sennikov M.Yu., Romanova Yu.V., Sycheva N.S., Ostroushko A.A. Homogeneous and polymer-supported catalysts in the oxidation of $\alpha$-pinene with oxygen. Russ. J. Org. Chem., 2004, 40(6), P. 790-794.

[191] Men'shikov S.Yu., Mishina Yu.V., Mikushina Yu.V., Ostroushko A.A. A comparative study of aerobic oxidation of turpentine. Russ. J. Appl. Chem., 2008, 81(1), P. 52-54.

[192] Ostroushko A.A., Sennikov M.Yu., Sycheva N.S. Features of photochemical reactions in polymer-salt compositions containing ammonium heptamolybdate and poly(vinyl alcohol). Russ. J. Inorg. Chem., 2005, 50(7), P. 1050-1054.

[193] Ostroushko A.A., Sennikov M.Yu. The Kinetics of Photochemical Processes in Polymer-Salt Systems. Russ. J. Phys. Chem. A, 2009, 83(1), P. 111-115.

[194] Ostroushko A.A., Sennikov M.Yu., Gerasimova E.L. Electrochemical and electrophysical parameters of polymer-salt compositions based on poly(vinyl alcohol) and ammonium heptamolybdate. Russ. J. Inorg. Chem., 2005, 50(3), P. 428-432.

[195] Ostroushko A.A., Mogil'Nikov Yu.V., Popov K.A. Thermal destruction of polymer-salt compositions containing d-metals in the form of oxygen-bearing anions. Inorg. Mat., 2000, 36(6), P. 603-611.

[196] Ostroushko A.A., Mogil'nikov Yu.V., Vilkova N.V., Popov K.A. Combined analysis of parameters and thermal behavior of polymer-salt formulations containing anionic d-metal species. Russ. J. Appl. Chem., 2000, 73(10), P. 1684-1690.

[197] Valiev E., Bogdanov S., Pirogov A., Teplykh A., Ostroushko A., Mogilnikov Yu. The formation processes of oxide phases from polymer-salt complexes of ammonium molybdate and tungstate. Phys. B: Cond. Mat., 2000, 276, P. 854-855.

[198] Bogdanov S.G., Ostroushko A.A., Valiev E.Z., Pirogov A.N., Teplykh A.E. Effect of acidity of polymer-salt compositions on the formation mechanism of the tungsten and molybdenum oxide particles. Poverkh. Rentgen. Sinkhr. i Nejtron. Issledov., 2004, 2, P. 21-33.

[199] Ostroushko A.A., Mikhalev D.S., Reshetnikova N.V. Stability of polymeric-salt gels used to synthesize complex-oxide materials. Rus. J. of Appl. Chem., 2002, 75(8), P. 1219-1222.

[200] Ostroushko A.A., Mogil'Nikov Y.V., Popov K.A., Vilkova N.V., Zhuravleva L.I., Ostroushko I.P. Interactions between $\mathrm{M}^{2+}$ and $\mathrm{M}^{3+}$ cations and d-metal complex anions in polymer-containing solutions. Russ. J. Inorg. Chem., 1999, 44(8), P. 1328-1334.

[201] Ostroushko A.A., Makarov A.M., Minyaev V.I. Oxidation of carbon in the presence of catalysts based on cesium lanthanum vanadate. Russ. J. Appl. Chem., 2004, 77(7), P. 1121-1129.

[202] Ostroushko A.A. Catalytic activity of metal ions in redox processes in polymer-salt systems during synthesis of mixed oxides. Inorg. Mat., 2004, 40(3), P. 259-263.

[203] Kingsley J.J., Patil K.C. A novel combustion process for the synthesis of fine particle $\alpha$-alumina and related oxide materials. Mater. Lett., 1988, 6(11/12), P. 427-432.

[204] Ianos R., Barvinschi P. Solution combustion synthesis of calcium zirconate, $\mathrm{CaZrO}_{3}$, powders. J. Solid. State. Chem., 2010, 183, P. 491-496.

[205] Prasanth C.S., Kumar H.P, Pazhani R., Solomon S., Thomas J.K. Synthesis, characterization and microwave dielectric properties of nanocrystalline $\mathrm{CaZrO}_{3}$ ceramics. J. Alloys Compd., 2008, 464, P. 306-309.

[206] Deganello F., Liotta L.F., Marci G., Fabbri E., Traversa E. Strontium and iron-doped barium cobaltite prepared by solution combustion synthesis: exploring a mixed-fuel approach for tailored intermediate temperature solid oxide fuel cell cathode materials. Mat. for Renew. and Sust. En., 2013, 2(1), P. 2-8.

[207] Deganello F., Marci G., Deganello G. Citrate-nitrate auto-combustion synthesis of perovskite-type nanopowders: a systematic approach. J. Europ. Ceram. Soc, 2009, 29(3), P. 439-450.

[208] Boobalan K., Varun A., Vijayaraghavan R., Chidambaram K., Kamachi Mudalic U. Facile, scalable synthesis of nanocrystalline calcium zirconate by the solution combustion method. Ceram. Int., 2014, 40(4), P. 5781-5786.

[209] Ostroushko A.A., Sennikov M.Yu. Thermochemical charge generation in polymer-salt films. Rus. J. of Inorg. Chem., 2005, 50(6), P. 933-936.

[210] Ostroushko A.A., Sennikov M.Yu. Thermochemical charge generation in polymer-salt films as a function of temperature. Rus. J. of Inorg. Chem., 2008, 53(8), P. 1172-1175.

[211] Lusheikin G.A. Polymer electrets. Moscow, Khimiya, 1976, 224 pp. (in Russian)

[212] Ostroushko A.A., Russkikh O.V., Kormil'tzev I.I., Kolosov V.Y., Tsvetkov D.S., Vylkov A.I. Study of nanostructured catalysts on the basis of complex oxides deposited on a carrier. J. Surf. Invest., 2011, 5(4), P. 677-682.

[213] Ostroushko A.A., Russkikh O.V., Filonova E.A., Melnikova A.A. A comprehensive analysis of processes of complex oxide materials synthesis, the influence of charge generating process on synthesis results. XX Mendeleev Congress on general and applied chemistry. Five-volumes book. Vol. 2a : abstracts. Ekaterinburg: Ural Branch of the Russian Academy of Sciences, 2016, P. 92. 
[214] Ivanov B.V., Lipilin A.S., Spirin A.V., Rempel Al.A., Paranin S.N., Khrustov B.R., Shkerin S.N., Valentsev A.V., Zhuravlev V.D. The formation of multilayer structures of solid oxide fuel cells. Int. Scien. J. for Altern. Energy. and Ecol., 2007, 2(46), P. 75-88. (in Russian) .

[215] Almjasheva O.V., Fedorov B.A., Smirnov A.V., Gusarov V.V. Size, morphology and structure of the particles of zirconia nanopowder obtained under hydrothermal conditions. Nanosystems: Physics, Chemistry, Mathematics, 2010, 1(1), P. 26-37. (in Russian)

[216] Vasilevskaya A., Almjasheva O.V., Gusarov V.V. Peculiarities of structural transformations in zirconia nanocrystals. J. Nanopart. Res., 2016, 18(188), P. 1-11.

[217] Ostroushko A.A., Udilov A.E. Some features of processes of formation of complex oxide products by pyrolysis of polymer-salt compositions. Izvestiya VUZov. Ser. Khimiya i Khim. Tehn., 2007, 50(10), P. 118-122. (in Russian) 